\title{
Modelling firn thickness evolution during the last deglaciation: constraints on sensitivity to temperature and impurities
}

\author{
Camille Bréant $^{1,2}$, Patricia Martinerie ${ }^{2}$, Anaïs Orsi ${ }^{1}$, Laurent Arnaud ${ }^{2}$, and Amaëlle Landais ${ }^{1}$ \\ ${ }^{1}$ Laboratoire des Sciences du Climat et de l'Environnement, UMR8212, CEA-CNRS-UPS/IPSL, Gif-sur-Yvette, France \\ ${ }^{2}$ Univ. Grenoble Alpes, CNRS, IRD, IGE, UMR5001, Grenoble, 38000, France \\ Correspondence to: Camille Bréant (camille.breant@ univ-grenoble-alpes.fr)
}

Received: 14 September 2016 - Discussion started: 12 October 2016

Revised: 1 June 2017 - Accepted: 2 June 2017 - Published: 13 July 2017

\begin{abstract}
The transformation of snow into ice is a complex phenomenon that is difficult to model. Depending on surface temperature and accumulation rate, it may take several decades to millennia for air to be entrapped in ice. The air is thus always younger than the surrounding ice. The resulting gas-ice age difference is essential to documenting the phasing between $\mathrm{CO}_{2}$ and temperature changes, especially during deglaciations. The air trapping depth can be inferred in the past using a firn densification model, or using $\delta^{15} \mathrm{~N}$ of air measured in ice cores.
\end{abstract}

All firn densification models applied to deglaciations show a large disagreement with $\delta^{15} \mathrm{~N}$ measurements at several sites in East Antarctica, predicting larger firn thickness during the Last Glacial Maximum, whereas $\delta^{15} \mathrm{~N}$ suggests a reduced firn thickness compared to the Holocene. Here we present modifications of the LGGE firn densification model, which significantly reduce the model-data mismatch for the gas trapping depth evolution over the last deglaciation at the coldest sites in East Antarctica (Vostok, Dome C), while preserving the good agreement between measured and modelled modern firn density profiles. In particular, we introduce a dependency of the creep factor on temperature and impurities in the firn densification rate calculation. The temperature influence intends to reflect the dominance of different mechanisms for firn compaction at different temperatures. We show that both the new temperature parameterization and the influence of impurities contribute to the increased agreement between modelled and measured $\delta^{15} \mathrm{~N}$ evolution during the last deglaciation at sites with low temperature and low accumulation rate, such as Dome C or Vostok. We find that a very low sensitivity of the densification rate to temperature has to be used in the coldest conditions. The inclusion of im- purity effects improves the agreement between modelled and measured $\delta^{15} \mathrm{~N}$ at cold East Antarctic sites during the last deglaciation, but deteriorates the agreement between modelled and measured $\delta^{15} \mathrm{~N}$ evolution at Greenland and Antarctic sites with high accumulation unless threshold effects are taken into account. We thus do not provide a definite solution to the firnification at very cold Antarctic sites but propose potential pathways for future studies.

\section{Introduction}

Ice cores are important tools to decipher the influence of different forcings on climate evolution. They are particularly useful for reconstructing the past variations in polar temperature and greenhouse gases. The longest record covers the last eight glacial-interglacial cycles (EPICA community members, 2004; Jouzel et al., 2007; Loulergue et al., 2008; Lüthi et al., 2008) and very-high-resolution climate records can be retrieved from ice cores drilled in high-accumulation regions (Marcott et al., 2014; Rhodes et al., 2015; WAIS Divide Project Members, 2013, 2015).

Polar ice is a porous medium and contains bubbles filled with ancient atmospheric air, allowing the reconstruction of the atmospheric composition in the past. The air is trapped at about $50-120 \mathrm{~m}$ under the ice sheet surface. Above that depth the interstitial air in firn pores remains in contact with the atmosphere. Consequently, the air is always younger than the surrounding ice, and this age difference, $\Delta$ age, can reach several millennia at the low temperature and accumulation rate sites of East Antarctica. 
A precise determination of $\Delta$ age is essential to quantify the link between temperature changes recorded in the water isotopic measurements on the ice phase and greenhouse gas concentrations recorded in the gas phase. Still, quantifying the temporal relationship between changes in greenhouse gas concentrations in air bubbles and changes in polar temperature recorded in the isotopic composition of the ice is not straightforward. One way to address this question is through the development of firn densification models that depict the progressive densification of snow to ice and the associated decrease in porosity. Below a certain threshold density, the pores seal off and the air is trapped. The firn densification models thus calculate the lock-in depth (hereafter LID) according to surface climatic conditions. A higher temperature accelerates the firn metamorphism and leads to a shallower LID. Conversely, a higher snow accumulation at the surface will have the effect of increasing the firn sinking speed and hence deepening the LID.

On glacial-interglacial timescales, increasing temperature is associated with increasing snow accumulation. Indeed, the thermodynamic effect dominates when dealing with longterm averages (several thousands of years), even if accumulation and temperature are not always correlated on millennial and centennial timescales in polar regions, especially in coastal areas (e.g. Fudge et al., 2016; Altnau et al., 2015). As a consequence, we observe joint increases in both accumulation and temperature for all available ice cores covering the last deglaciation. In the firn densification model, both effects partially compensate for each other, with the temperature effect being dominant in the current densification models for the LID simulation over glacial-interglacial transitions in deep drilling sites of the East Antarctic plateau, hence leading to the modelled LID decrease.

A first class of densification models is based on an empirical approach to linking accumulation rate and temperature at different polar sites to densification rates (allowing the match between the modelled and the measured density profiles) (e.g. Herron and Langway, 1980). The Herron and Langway (1980) model assumes that the porosity (air space in the firn) variations directly relate to the weight of the overlying snow, hence the accumulation rate. A temperature dependence following an Arrhenius law is also implemented to account for a more rapid compaction at higher temperature. Finally, the exact model sensitivity to temperature and accumulation rate is adjusted empirically in order to simulate observed density profiles. Measured density profiles exhibit different densification rates above and below $550 \mathrm{~kg} \mathrm{~m}^{-3}$ so that different empirical laws are used for densities above and below this threshold. Indeed, $550 \mathrm{~kg} \mathrm{~m}^{-3}$ corresponds to the observed maximum packing density of snow (e.g. Anderson and Benson, 1963), hence to a change in the driving mechanism of firnification.

Despite its simple empirical description, and although more sophisticated empirical models have been developed (Arthern et al., 2010; Helsen et al., 2008; e.g. Li and Zwally,
2004; Ligtenberg et al., 2015), the Herron and Langway (1980) firn model often provides good-quality results and is still used in a number of ice core studies (e.g. Buizert et al., 2015; Overly et al., 2016; Lundin et al., 2017). However, its validity is questionable when used outside of its range of calibration, such as for glacial periods at cold sites on the East Antarctic plateau for which no present-day analogue exists. As a consequence, firn models including a more physical description of densification have been developed (e.g. Arnaud et al., 2000; Salamatin et al., 2009). The model developed over the past 30 years at Laboratoire de Glaciologie et Géophysique de l'Environnement (LGGE) (Arnaud et al., 2000; Barnola et al., 1991; Goujon et al., 2003; Pimienta, 1987) aims at using a physical approach that remains sufficiently simple to be used on very long timescales (covering the ice core record length). More complex models, explicitly representing the material microstructure, have been developed but require a lot more computing time (Hagenmuller et al., 2015; Miller et al., 2003). Still, the simplified physical mechanisms in our model include parameters adjusted through comparison of modelled and measured present-day firn density profiles, which may induce biased results outside the range of calibration.

In parallel to firn densification modelling, past firn LID can also be determined using the $\delta^{15} \mathrm{~N}$ measurements in the air trapped in ice cores. Indeed, in the absence of transient thermal gradients, the $\delta^{15} \mathrm{~N}$ trapped at the bottom of the firn is mainly related to the diffusive column height (DCH). This is due to gravitational settling in the firn following the steadystate barometric equation (Craig et al., 1988; Schwander, 1989; Sowers et al., 1989):

$$
\begin{aligned}
\delta^{15} \mathrm{~N}_{\text {grav }} & =\left[\exp \left(\frac{\Delta m g z}{R T_{\text {mean }}}\right)-1\right] 1000 \\
& \approx \frac{g z}{R T_{\text {mean }}} \Delta m \times 1000(\% \circ),
\end{aligned}
$$

where $\Delta m$ is the mass difference $\left(\mathrm{kg} \mathrm{mol}^{-1}\right)$ between ${ }^{15} \mathrm{~N}$ and ${ }^{14} \mathrm{~N}, g$ is the gravitational acceleration $\left(9.8 \mathrm{~m} \mathrm{~s}^{-2}\right), R$ is the gas constant $\left(8.314 \mathrm{~J} \mathrm{~mol}^{-1} \mathrm{~K}^{-1}\right), T_{\text {mean }}$ is the mean firn temperature $(\mathrm{K})$, and $z$ is the noted DCH. In the absence of convection at the top of the firn, the firn LID is equal to the $\mathrm{DCH}$.

In Greenland ice cores, where strong and abrupt surface temperature changes occurred during the last glacial period and deglaciation, $\delta^{15} \mathrm{~N}$ is also affected by strong thermal fractionation. An abrupt warming (on the order of $10^{\circ} \mathrm{C}$ in less than 50 years) indeed induces a transient temperature gradient of a few degrees in the firn (Severinghaus et al., 1998; Guillevic et al., 2013; Kindler et al., 2014). $\delta^{15} \mathrm{~N}$ is thus modified as $\delta^{15} \mathrm{~N}_{\text {therm }}=\Omega \cdot \Delta T$, where $\Omega$ is the thermal fractionation coefficient (Grachev and Severinghaus, 2003), and this thermal signal is superimposed on the gravitational one (the $\delta^{15} \mathrm{~N}_{\text {therm }}$ observed is lower than $0.15 \%$ ) in most cases. 


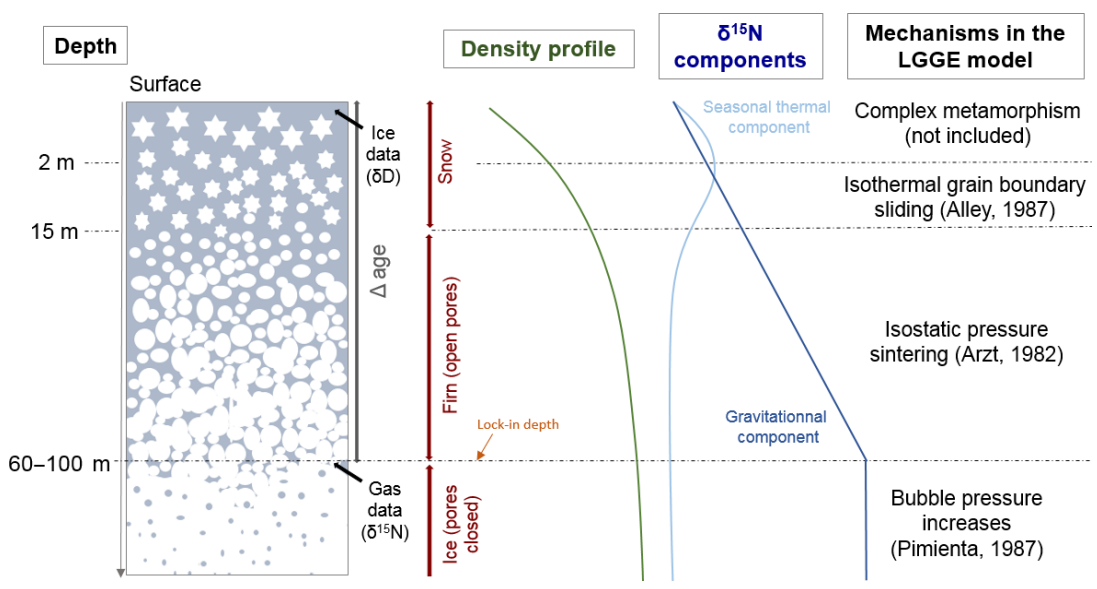

Figure 1. Overview of snow densification and influence on the $\delta^{15} \mathrm{~N}$ profile in the absence of any significant convective zone as observed in most present-day $\delta^{15} \mathrm{~N}$ profiles (Landais et al., 2006; Witrant et al., 2012).

While models can reproduce the observed $\delta^{15} \mathrm{~N}$ at Greenland sites over the last climatic cycle, a strong mismatch is observed for cold Antarctic sites, especially on the East Antarctic plateau (Dreyfus et al., 2010). In particular, both the empirical and physical models predict a decrease in the LID during glacial to interglacial transitions (Goujon et al., 2003; Sowers et al., 1992), while the $\delta^{15} \mathrm{~N}$ evolution indicates an increase in the LID (Capron et al., 2013; Sowers et al., 1992). The decrease in the LID in the models is caused by the increase in temperature during the deglaciation, which has a stronger impact than the increase in the accumulation rate. The differences in modelled and measured $\delta^{15} \mathrm{~N}$ for glacial periods at cold sites on the East Antarctic plateau have important consequences for the $\Delta$ age estimate and hence the ice core chronology: using the firn densification models, the modelled $\Delta$ age for the glacial period at Vostok and Dome C is too large by several centuries (Loulergue et al., 2007; Parrenin et al., 2012).

Several hypotheses have already been invoked to explain the $\delta^{15} \mathrm{~N}$ model-data mismatch in Antarctica as detailed in Landais et al. (2006), Dreyfus et al. (2010), and Capron et al. (2013). First, the firnification models have been developed and tuned for reproducing present-day density profiles and it is questionable to apply them to glacial climate conditions in Antarctica for which no present-day analogues are available. Second, increasing impurity concentration has been suggested to fasten firn densification during the glacial period (Freitag et al., 2013; Hörhold et al., 2012). Third, a $\sim 20 \mathrm{~m}$ deep convective zone has been evidenced in the megadunes region in Antarctica (Severinghaus and Battle, 2006), hence suggesting that deep convective zones can develop in glacial periods in Antarctica and explain the mismatch between firn densification model and $\delta^{15} \mathrm{~N}$ data (Caillon et al., 2003). This hypothesis can explain the mismatch between modelled and measured $\delta^{15} \mathrm{~N}$ at EPICA Dronning Maud Land (EDML) during the glacial period by invoking a $10 \mathrm{~m}$ convective zone
(Landais et al., 2006). However, it has been ruled out for explaining the strong mismatch between model and $\delta^{15} \mathrm{~N}$ data at EPICA Dome C (EDC) for the last glacial period (Parrenin et al., 2012). Fourth, firn densification is very sensitive to changes in temperature and accumulation rate so that uncertainties in the surface climate parameters can lead to a biased value of the modelled LID and hence $\delta^{15} \mathrm{~N}$. Fifth, a significant thermal fractionation signal can affect the total $\delta^{15} \mathrm{~N}$ signal. However, this hypothesis has been ruled out by Dreyfus et al. (2010) based on $\delta^{15} \mathrm{~N}$ and $\delta^{40} \mathrm{Ar}$ data on the last deglaciation at EDC.

In this study, we test whether simple modifications of the LGGE model can reduce the model-data mismatch for the LID evolution over the last deglaciation at sites on the East Antarctic plateau. In particular, it has been suggested by Capron et al. (2013) that the firn densification rate is underestimated at very low temperatures. We also examine the possible influence of impurity concentration in the LGGE model following the approach from Freitag et al. (2013) and Hörhold et al. (2012). The paper is organized as follows. In the next section (Sect. 2) we present the physical model with a focus on recent modifications. In Sect. 3, we compare the model output to present-day observed firn density profiles and $\delta^{15} \mathrm{~N}$ data over the last deglaciation at different polar sites from Greenland and Antarctica. Section 4 summarizes our conclusions.

\section{Densification model description and improvements}

An in-depth description of the LGGE firn densification model is provided in Goujon et al. (2003). Here we first briefly summarize its content and then detail the modifications introduced in this study. The main inputs to the model are temperature and snow accumulation rate (Text S1 in the Supplement). During climatic transitions occurring on timescales similar to or shorter than firnification, the prop- 
agation of the atmospheric temperature signal into the firn has to be taken into account (Schwander et al., 1997). The thermomechanical model comprises four modules. A simple ice sheet flow module calculates the vertical speed in a 1-D firn and ice column. This vertical speed is used in the thermal module to calculate heat advection. The thermal module solves the heat transfer equation, which combines heat advection and heat diffusion across the whole ice sheet thickness. Using the resulting temperature profile in the firn, the mechanical module evaluates the densification rates resulting from three successive mechanisms detailed below. Finally, a gas-age module keeps track of snow layers sinking in a Lagrangian mode and uses a gas trapping criterion in order to evaluate the gas trapping depth and the ice age-gas age difference $(\Delta$ age $)$.

The model does not take into account the complex mechanisms associated with snow metamorphisms under the influence of strong temperature gradients, wind, and sublimation-recondensation (Colbeck, 1983; Kojima, 1967; Mellor, 1964). This kind of metamorphism affects the 1-3 m at the top of the firn and has a minor role in the modelled LID.

Below this depth, the densification of snow into ice has been divided into three stages (e.g. Maeno and Ebinuma, 1983, and references therein; Fig. 1). The first stage, named snow densification as in Goujon et al. (2003), corresponds to a rearrangement and packing of snow grains until it approaches the maximum compaction at a density of about $550 \mathrm{~kg} \mathrm{~m}^{-3}$ (or 0.6 on a unitless scale relative to the density of pure ice) defined as the critical density. The second stage represents the firn densification by sintering associated with viscoplastic deformation. Finally, when the bubbles are closed (at a relative density of about 0.9 ), the ice densification is driven by the difference in pressure between air trapped in bubbles and the solid ice matrix subject to the weight of the overlying firn structure. In reality, the adjacent densification mechanisms likely coexist at intermediate densities. Below, we further describe the mechanical structure of the model with a focus on recent modifications and proposed parameterizations. We refer to Arnaud et al. (2000) and Goujon et al. (2003) for more details.

The model uses macroscopic (simplified) mechanical laws, which link the densification speed $\left(\mathrm{d} D_{\text {rel }} / \mathrm{d} t\right.$, in terms of relative density $\left(D_{\text {rel }}=\frac{\rho}{\rho_{\text {ice. }}}\right)$ ) to its main driving force: the overburden pressure of overlying snow. It is important to note that in our model, the accumulation rate influences firn densification only through the overburden pressure:

$$
P(h)=g \int_{o}^{h} \rho \mathrm{d} z,
$$

where $g$ is the gravity constant and $\rho$ is the density in kilograms per cubic metre. This differs from the Herron and Langway (1980) model in which the effect of accumulation rate is adjusted and expressed with a different power law for snow and firn densification rates. In porous materials, the overburden pressure $P$ is transmitted through contact areas between grains rather than the entire surface of the material. This is expressed by replacing $P$ with an effective pressure $P_{\text {eff }}$ in mechanical stress-strain laws. The relationship between $P$ and $P_{\text {eff }}$ depends on the material geometry (e.g. Eq. A4 in Goujon et al., 2003). A higher temperature $(T)$ facilitates the deformation of materials, and this effect is commonly represented by an Arrhenius law: $e^{\left(\frac{-Q}{R T}\right)}$, where $R$ is the gas constant and $Q$ is an activation energy. The value of the activation energy depends on the underlying physical mechanism of ice and snow deformation, but Arrhenius expressions cannot represent deformation effects linked to ice melting. The relationships between densification speed and overburden pressure take the following general form:

$\frac{\mathrm{d} D_{\text {rel }}}{\mathrm{d} t}=A_{0} \times e^{\left(-\frac{Q}{R T}\right)} \times\left(P_{\mathrm{eff}}\right)^{n}$,

where $A_{0}=7.89 \times 10^{-15} \mathrm{~Pa}^{-3} \mathrm{~s}^{-1}$ (Goujon et al., 2003; Eq. A5) and $n$ is the stress exponent. In the rest of the paper, we will refer to $A=A_{0} \times e^{\left(-\frac{Q}{R T}\right)}$ as the creep parameter.

\subsection{Densification of snow}

During the first stage, the dominant snow densification mechanism is assumed to be isothermal boundary sliding and the model of Alley (1987) is used (Fig. 1). The geometrical approximation used to build the model represents snow as equal size spheres with a number of contacts between neighbours increasing with density. In the LGGE model, the Alley mechanism is implemented as Eq. (A1) in Goujon et al. (2003):

$$
\frac{\mathrm{d} D_{\text {rel }}}{\mathrm{d} t}=\gamma\left(\frac{P}{D_{\text {rel }}^{2}}\right)\left(1-\frac{5}{3} \times D_{\text {rel }}\right) .
$$

It directly relates to Eq. (5) in Alley (1987):

$$
\frac{\mathrm{d} D_{\mathrm{rel}}}{\mathrm{d} t}=\frac{2}{15} \times \frac{\lambda}{v} \times \frac{R}{r^{2}} \times\left(1-\frac{5}{3} \cdot D_{\mathrm{rel}}\right) \times \frac{P}{D_{\mathrm{rel}}^{2}},
$$

where $\lambda$ is the bond thickness, $v$ the bond viscosity, $R$ the grain radius, and $r$ the bond radius. $P$ is expressed as a function of accumulation and gravity (Eq. 2).

The important simplification in the LGGE model is the replacement of geometry-dependent parameters, not available for past conditions, with a variable $\gamma$, adjusted in order to obtain a continuous densification rate at the boundary between the first and the second stages of densification.

A first modification in this module consists of extending the Alley (1987) scheme to the upper $2 \mathrm{~m}$ of the firn rather than using a constant density value. Indeed, since the model is not able to represent the metamorphism of the first $2 \mathrm{~m}$, we impose a constant pressure of 0.1 bar (see Eq. 6), which is an approximation of the pressure at $2-3 \mathrm{~m}$ depth. It results in a 
nearly constant densification rate in the top $2-3 \mathrm{~m}$ rather than a constant density in the top $2 \mathrm{~m}$.

The second modification concerns the transition between the snow and firn densification stages at the relative density of 0.6. In Eq. (4), the term $\left(1-\frac{5}{3} \times D_{\text {rel }}\right)$ implies that the densification speed drops to zero at $D_{\text {rel }}=\frac{3}{5}$ (i.e. 0.6 the maximal compaction density). The second stage of densification (firn densification) is driven by an important overburden pressure on the contact area hence associated with a high densification speed. The transition between the sharp decrease in the densification speed for $D_{\text {rel }}$ values close to 0.6 in the snow densification stage and the high densification speed at the beginning of the firn densification (i.e. in the same range of values for $D_{\text {rel }}$ ) causes some model instabilities, especially at sites with high temperature and accumulation rate. In order to improve the model stability, we go back to the definition of the term $\left(1-\frac{5}{3} \times D_{\text {rel }}\right)$ in the initial formulation of Alley (1987). This term relies on a correlation between the coordination number $(N)$ and relative density: $D_{\text {rel }}=10 N$. We slightly modified this relationship and impose $D_{\text {rel }}=10 N-0.5$, which better matches the data in Fig. 1 of Alley (1987). This results in replacing the term $\left(1-\frac{5}{3} \times D_{\text {rel }}\right)$ in Eq. (4) with $\left(1+\frac{0.5}{6}-\frac{5}{3} \times D_{\text {rel }}\right)$. This modification shifts the density at which the densification rate becomes zero from 0.6 to 0.65 and suppresses the model instability.

We also examine the effect of temperature on the firststage densification mechanism and on the critical density. Alley (1987) calculated an activation energy of $41 \mathrm{~kJ} \mathrm{~mol}^{-1}$ related to $(v)$, consistent with recommended values for grainboundary diffusion $\left(42 \mathrm{~kJ} \mathrm{~mol}^{-1}\right)$ or measured from grain growth rate (Alley, 1987, and references therein). In Goujon et al. (2003), no explicit temperature effect is used but the parameter $\gamma$ varies by several orders of magnitude from site to site. The parameter $\gamma$ is calculated to maintain a continuous densification rate between the first and second stages at a chosen critical density. We translate the variations from site to site of $\gamma=(2 \lambda R) /\left(15 v r^{2}\right)$, where $\lambda$ is the bond thickness, $R$ the grain radius, $v$ the bond viscosity, and $r$ the bond radius (as in Eq. 5), into $\gamma=\gamma^{\prime} \exp (-Q / R T)$ and calculate the activation energy $Q$ using a classical logarithmic plot as a function of 1000/T (see e.g. Herron and Langway, 1980). We obtain a value of $48 \mathrm{~kJ} \mathrm{~mol}^{-1}$. Using the revised temperature dependency for the firn densification mechanism (see next section), a slightly higher value of $Q=49.5 \mathrm{~kJ} \mathrm{~mol}^{-1}$ is calculated (Fig. S1 in the Supplement). This is fairly similar to the values in Alley (1987) but much higher than the value in the upper firn of the Herron and Langway (1980) model: $10.16 \mathrm{~kJ} \mathrm{~mol}^{-1}$. Incorporating this explicit temperature dependency term, we obtain our new final expression for the upper firn densification rate:

$$
\begin{aligned}
\frac{\mathrm{d} D_{\text {rel }}}{\mathrm{d} t} & =\gamma^{\prime}\left(\frac{\max (P, 0.1 \text { bar })}{D_{\text {rel }}^{2}}\right)\left(1+\frac{0.5}{6}-\frac{5}{3} \times D_{\text {rel }}\right) \\
& \times e^{\left(-\frac{Q}{R T}\right)},
\end{aligned}
$$

where $\gamma^{\prime} \times e^{\left(-\frac{Q}{R T}\right)}$ is equivalent to $\gamma$ in Eq. (4). However, $\gamma$ varies by 2 orders of magnitude as a function of temperature, whereas $\gamma^{\prime}$ remains in the range from $0.5 \times 10^{9}$ to $2 \times 10^{9} \mathrm{bar}^{-1}$.

Finally, the temperature dependency of the critical density, which defines the boundary between the first and second stage densification mechanisms, is also re-evaluated. According to Benson (1960), Arnaud (1997), and Arnaud et al. (2000), this critical density increases with temperature. However, the slope change in density profiles associated with the critical density may be difficult to locate and the Benson (1960) and Arnaud (1997) parameterizations are based on only a few observation sites. We evaluate the critical density values, which allow the best match of density data by our model results at 22 sites and do not find any correlation between critical density and temperature or accumulation rate (Fig. S2). We thus remove this dependency with temperature included in the old version of the LGGE model and use a mean relative critical density of 0.56 at the boundary between the first and second stages of densification in the new version of the model. The effect of surface density was also tested and does not have a strong impact on the model results (Fig. S3).

\subsection{Densification of firn}

At this stage, the observation of density profiles with depth suggests that the densification rate is controlled by a classical power law creep as used for ice deformation (Arzt et al., 1983; Maeno and Ebinuma, 1983; Wilkinson and Ashby, 1975). Arzt (1982) proposed a pressure sintering mechanism for firn densification following a power law creep and taking into account the progressive increase in the coordination number. He solved the geometrical problem of compressing a random dense packing of monosized spheres with associated deformation of each sphere into irregular polyhedra. Equation (23) of Arzt (1982) is directly used in the firn densification model.

\subsubsection{Revised temperature sensitivity of the firn densification rate}

A strong assumption in the firn densification module is the constant activation energy corresponding to self-diffusion of ice $\left(60 \mathrm{~kJ} \mathrm{~mol}^{-1}\right)$. This choice corresponds to a unique mechanism supposed to drive densification. Densification is thus assumed to be driven by dislocation creep (Ebinuma and Maeno, 1987) in which the associated mechanism is lattice 


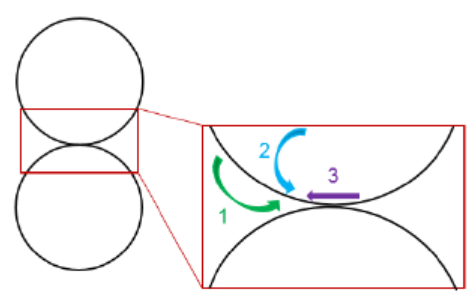

- (1) Mechanism 1: close to melting temperature - mass transfer by diffusion (potential mechanism for high temperature)

- (2) Mechanism 2: low temperature - lattice diffusion (classical mechanism)

- (3) Mechanism 3: very low temperature - boundary diffusion from grain boundary (potential mechanism for low temperature)

Figure 2. Different sintering mechanisms of snow for different temperatures proposed by analogy with the hot ceramic sintering (inspired by Fig. 1 in Ashby, 1974). Note that more sintering mechanisms can be found in the literature: in their initial figure, Ashby (1974) mentioned six different mechanisms but only two permit densification (lattice diffusion and boundary diffusion from grain boundary). The attributions of three different mechanisms for the firn densification model based on the powder aggregate study from Ashby (1974) is only a working hypothesis here.

diffusion or self-diffusion. On the grain scale, we can describe the lattice diffusion processes associated with dislocation as diffusion within the grain volume of a water molecule from a dislocation site in the ice lattice to the grain neck in order to decrease the energy associated with grain boundaries (Blackford, 2007). Typically, an activation energy of 60 to $75 \mathrm{~kJ} \mathrm{~mol}^{-1}$ is associated with this mechanism (Arthern et al., 2010; Barnes et al., 1971; Pimienta and Duval, 1987; Ramseier, 1967, and references therein).

However, multiple studies have already shown that several (six or more) mechanisms can act together for firn or ceramic sintering (Ashby, 1974; Blackford, 2007; Maeno and Ebinuma, 1983; Wilkinson and Ashby, 1975): lattice diffusion from dislocations, grain surfaces, or grain boundaries; vapour transport; and surface and boundary diffusions. In order to properly take these different mechanisms into account, different activation energies (one activation energy per mechanism) should ideally be introduced in the firn densification model. Actually, it has been observed that, at warm temperature, an activation energy significantly higher than $60 \mathrm{~kJ} \mathrm{~mol}^{-1}$ could be favoured (up to $177 \mathrm{~kJ} \mathrm{~mol}^{-1}$ between -1 and $-5^{\circ} \mathrm{C}$; Jacka and $\mathrm{Li}, 1994$ ) in order to best fit density profiles with firn densification models (Arthern et al., 2010; Barnes et al., 1971; Jacka and Li, 1994; Morgan, 1991). This suggests that a mechanism different from lattice diffusion is dominant for grain compaction at high temperature (i.e. higher than $\left.-10^{\circ} \mathrm{C}\right)$. At low temperature $\left(-50^{\circ} \mathrm{C}\right)$, by analogy with ceramic sintering, lattice diffusion from the surface of the grains and/or boundary diffusion from grain boundaries should be favoured (Ashby, 1974). The activation energy for surface diffusion is estimated to be in the range of 14-38 kJ mol${ }^{-1}$ (Jung et al., 2004; Nie et al., 2009).

Following these arguments and despite the lack of experimental constraints to test this assumption, we propose a new heuristic parameterization of the activation energy in the LGGE firn densification model that increases the firn densification rate at low temperatures. We have thus enabled the introduction of three adjusted activation energies as proposed in Table 1 and Fig. 2. We have replaced the creep parameter in Eq. (3) with

$A=A_{0} \times\left(a_{1} \times e^{\frac{-Q_{1}}{R T}}+a_{2} \times e^{\frac{-Q_{2}}{R T}}+a_{3} \times e^{\frac{-Q_{3}}{R T}}\right)$.

We have chosen a minimal number of mechanisms (Eq. 3) for simplicity in the following but the conclusions of our work would not be affected by a choice of more mechanisms.

When building the new parameterization of the activation energy (Eq. 7), the determination of $Q_{1}, Q_{2}$, and $Q_{3}$ on the one side and $a_{1}, a_{2}$, and $a_{3}$ on the other side are not independent of each other. We first determine three temperature ranges corresponding to the dominant mechanisms. Then we attribute values to the activation energies $Q_{1}, Q_{2}$, and $Q_{3}$. The coefficients $a_{1}, a_{2}$, and $a_{3}$ are finally adjusted to produce the expected evolution of the creep parameter with temperature, to best reproduce $\delta^{15} \mathrm{~N}$ evolution over deglaciations (Sect. 3.2) and respect the firn density profiles available (Sect. 3.1).

Hundreds of sensitivity tests have been performed imposing three activation energies at three different typical temperatures, $T_{i}$. The initial values for $Q_{i}$ are chosen as explained above (high value for $Q_{1}$, Jacka and Li, 1994; classical value between 60 and $70 \mathrm{~kJ} \mathrm{~mol}^{-1}$ for $Q_{2}$; and low value for $Q_{3}$ to increase the densification rate at low temperature). The initial values for $a_{i}$ are derived through $a_{i} \cdot \exp \left(-Q_{i} / R T_{i}\right)=$ $a_{0} \cdot \exp \left(-60000 / R T_{i}\right)$ and variations around the initial values of $Q_{i}$ and $a_{i}$ are randomly generated. Only the values leading to realistic densification speed are kept and we found the optimal tuning through reduction of the mismatch between model and data, especially for the deglacial amplitude of $\delta^{15} \mathrm{~N}$ in Dome $\mathrm{C}$ and Vostok. The constraint of keeping a correct agreement of model results with present-day density profiles and for the last deglaciation at warm sites strongly reduces the possible choices of $a_{i}$ and $Q_{i}$ (Sect. 3). The best value obtained for $Q_{3}$ is lower than published values for surface or boundary diffusion but is necessary to reproduce the deglaciation at cold East Antarctic sites. Sensitivity test C will illustrate the effect of using a higher value. 
Table 1. Preferred set of values for the three activation energies and associated pre-exponential constants.

\begin{tabular}{ll}
\hline Activation energy $\left(\mathrm{J} \mathrm{mol}^{-1}\right)$ & Coefficient \\
\hline$Q_{1}=110000$ & $a_{1}=1.05 \times 10^{9}$ \\
$Q_{2}=75000$ & $a_{2}=1400$ \\
$Q_{3}=1500$ & $a_{3}=6.0 \times 10^{-15}$ \\
\hline
\end{tabular}

The resulting expression for the creep parameter $A$ (Eq. 7) does not strongly differ from using simply $A=A_{0} \times$ $e^{\left(-\frac{60000}{R T}\right)}$, as used in the original model. To illustrate this point, we calculated an equivalent activation energy, $Q_{\text {eq }}$, such that $A=A_{0} \times e^{\left(-\frac{Q_{\mathrm{eq}}(T)}{R T}\right)}$, and found that $Q_{\mathrm{eq}}$ varies between 54 and $61 \mathrm{~kJ} \mathrm{~mol}^{-1}$ (Fig. S4). Thus, only moderate changes to the densification equation are needed to improve the behaviour of the model at cold temperature. In addition, only moderate changes in $Q_{\text {eq }}$ are allowed to preserve the consistency between model results and present-day density profiles.

\subsubsection{Sensitivity of the firn densification rate to impurities}

Firn densification can be influenced by impurity content in snow. Alley (1987) already suggested that grain growth is influenced by impurities dissolved in ice and that impurities in the grain boundaries affect the relative movement of snow grains. More recently, Hörhold et al. (2012) observed a correlation between the small-scale variability in density and calcium concentration in Greenland and Antarctic firn cores. Based on this observation, Freitag et al. (2013) proposed that the densification rate depends on the impurity content. They implemented an impurity parameterization in two widely used densification models (Herron and Langway, 1980; Barnola et al., 1991) and were able to reproduce the density variability in two firn cores from Greenland and Antarctica.

We have implemented this parameterization in our model with the simple assumption that the impurity effect is the same for all mechanisms. It allows us to keep the number of tunable parameters to a minimum, even though this assumption is probably not correct for the vapour diffusion process. Note however that this will not affect the applications discussed below since vapour diffusion is only important for warm sites. Concretely, we start again from the evolution of the creep parameter with respect to temperature given in Eq. (7) and add a dependency to calcium concentration such as

$$
\begin{aligned}
& \text { if }\left[\mathrm{Ca}^{2+}\right]>\left[\mathrm{Ca}^{2+}\right]_{\text {crit }}: \\
& \qquad Q^{\prime}=f_{1} \times\left[1-\beta \ln \left(\frac{\left[\mathrm{Ca}^{2+}\right]}{\left[\mathrm{Ca}^{2+}\right]_{\text {crit }}}\right)\right] \times Q \\
& \text { if }\left[\mathrm{Ca}^{2+}\right]<\left[\mathrm{Ca}^{2+}\right]_{\text {crit }}: Q^{\prime}=f_{1} \times Q,
\end{aligned}
$$

with $\left[\mathrm{Ca}^{2+}\right]_{\text {crit }}=0.5 \mathrm{ng} \mathrm{g}^{-1}$ (the detection limit of continuous flow analysis). $Q^{\prime}$ represents the new activation energy calculated as a function of the calcium concentration for each site. Our main simulations are performed with the $f_{1}$ and $\beta$ calculated by Freitag et al. (2013) for application within the Herron and Langway model: $f_{1}=1.025$ and $\beta=$ 0.01 . Using the values for application within the PimientaBarnola model $\left(f_{1}=1.015, \beta=0.0105\right)$ leads to similar results (Sect. 3.2). For a first evaluation of the impurity effect in our model, both the temperature and impurity effects are combined through the application of Eqs. (8) and (9) to each of the three different activation energies $Q_{1}, Q_{2}$, and $Q_{3}$. We use raw data of the calcium concentration for all the sites when available even if questions may arise as to whether calcium concentration is the best diagnostic for dust content.

The values of $a_{i}$ and $Q_{i}$ were not readjusted after the implementation of impurity effects to avoid adding tuning parameters. Still, because the large range of calcium concentrations encountered in past climate conditions has a strong impact on model results, this may be a solution to reduce the model-data mismatch. This is explored in Sect. 3 through a sensitivity test $\mathrm{D}$. In the same section, we will also propose a modification of the Freitag parameterization using thresholds to reduce the model-data mismatch.

\subsection{Densification of ice}

As in Goujon et al. (2003), the final densification stage begins at the close-off density derived from air content measurements in mature ice. Further porosity reduction results in an air pressure increase in the bubbles (Martinerie et al., 1992, Appendix 1). This density is calculated using the temperature-dependent close-off pore volume given by Martinerie et al. (1994). Further densification of this bubbly ice is driven by the pressure difference between ice matrix and the air in bubbles (Maeno and Ebinuma, 1983; Pimienta, 1987). The densification rate strongly decreases with depth as these two opposite pressures tend to balance each other out (Goujon et al., 2003). This stage is not essential for this study since $\delta^{15} \mathrm{~N}$ entrapped in air bubbles does not evolve anymore.

\subsection{Lock-in depth}

In the previous version of the model, the LID was computed as a fixed close-to-total porosity ratio. The ratio value used has been adjusted for each drilling site. For example, it is $21 \%$ for Vostok and $13 \%$ at Summit in Goujon et al. (2003), 

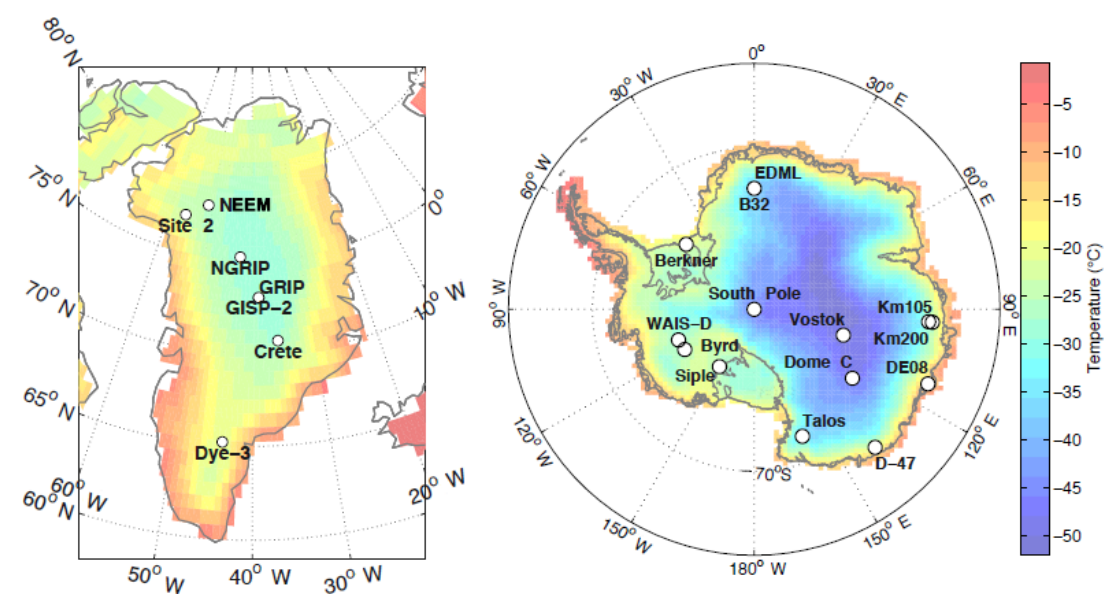

Figure 3. Maps of Greenland and Antarctica showing field sites and mean annual temperature from ERA-Interim (Dee et al., 2011).

but it was time independent and thus insensitive to climate. We revised the LID definition in order to relate its presentday geographic variations to climatic parameters.

Ideally, $\delta^{15} \mathrm{~N}$ profiles in the open porosity of the firn follow the barometric slope in the diffusive zone and show no variations in the lock-in zone. However, $\delta^{15} \mathrm{~N}$ data can deviate from this behaviour, especially at the very-lowaccumulation-rate sites such as Dome C, Vostok, or Dome Fuji, where no $\delta^{15} \mathrm{~N}$ plateau is observed in the lock-in zone (Bender et al., 1994; Kawamura et al., 2006; Landais et al., 2006). Moreover, as we aim at comparing our model results with $\delta^{15} \mathrm{~N}$ data in deep ice cores, the most consistent LID definition should refer to $\delta^{15} \mathrm{~N}$ data in mature ice but very few measurements are available for recent ice. Systematic $\delta^{15} \mathrm{~N}$ measurements in the closed porosity of the deep firn or recently formed mature ice would be very helpful to better constrain the LID in the future. We take advantage of recent advances in gas transport modelling (Witrant et al., 2012) that allowed correct simulation of the $\delta^{15} \mathrm{~N}$ behaviour in deep firn. Observations of modern firn air profiles show that the thickness of the lock-in zone (the zone in the deep firn with constant $\delta^{15} \mathrm{~N}$ ) increases when the snow accumulation rate increases (Witrant et al., 2012). We estimate $\delta^{15} \mathrm{~N}$ in ice, i.e. after complete bubble closure, at 12 firn air-pumping sites with the Witrant et al. (2012) model. For each site, the lockin density $\left(\rho_{\mathrm{LI}}\right)$ is then defined as the density at which the modelled $\delta^{15} \mathrm{~N}$ value in the open porosity of the firn equals the modelled $\delta^{15} \mathrm{~N}$ in ice. The resulting lock-in density is strongly related to the accumulation rate (Fig. S5). As a result, we parameterized the lock-in density $\left(\rho_{\mathrm{LI}}\right)$ as a function of the accumulation rate, following

$\rho_{\mathrm{LI}}=1.43 \times 10^{-2} \times \ln (1 / A c)+0.783$.

This parameterization leads to $\rho_{\mathrm{LI}}$ variations in the range $780-840 \mathrm{~kg} \mathrm{~m}^{-3}$ (Fig. S5) and a much better agreement between the modelled LID and $\delta^{15} \mathrm{~N}$ measured in firn samples at available sites than when using a fixed close-to-total poros- ity ratio. However, when used for simulating the LID during glacial periods with extremely low accumulation rate, it can predict a lock-in density that is higher than the close-off density, which is unrealistic. We thus also added a threshold in our new definition of the lock-in density: when $\rho_{\mathrm{LI}}$ exceeds the close-off density ( $\rho_{\mathrm{CO}}$, Sect. 2.3 ), we impose $\rho_{\mathrm{LI}}$ to be equal to $\rho_{\mathrm{CO}}$.

\section{Results}

\subsection{Firn density profiles}

We assessed the behaviour of the model by comparing measured and modelled firn density profiles from 22 sites from Greenland and Antarctica (Fig. 3). Figure 4 shows this comparison at Byrd, NEEM, Dome C, and Vostok, and other sites are displayed in the Supplement (Fig. S6). A polynomial fit was adjusted to the density data in order to facilitate the comparison with model results. The data dispersion around the fit can be due to natural density variations and/or measurement uncertainties.

A comparison of snow density measurement methodologies concluded that uncertainties are about $10 \%$ (Proksch et al., 2016). Moreover, although firn density profiles are often used, the measurement technique is not always well documented. Efforts were made in this study to mention the methodology when available (Table S1 in the Supplement). At high densities (below bubble closure depth), the hydrostatic weighing technique is expected to be about 10 times more precise than simple volume and mass measurements (Gow, 1968) but is rarely used, although it is important to correctly evaluate the fairly small density difference with pure ice density. We should note that the agreement between our model results and data is good at high densities for the three sites where the hydrostatic weighing technique was used: Site 2 and D-47 (Fig. S6) as well as Byrd (Fig. 4). 
High-resolution measurements on small samples often aim at documenting the natural variability in density. Our model only simulates bulk density, and to illustrate a meaningful comparison, the highest-resolution data (at DE08, B29, B32, and Dome C) were averaged over $0.25 \mathrm{~m}$ windows before being plotted. At some sites, a similar averaging was already performed before data publication (e.g. $1 \mathrm{~m}$ averaging at Byrd and Site 2, $0.5 \mathrm{~m}$ averaging at Mizuho). At a large number of sites, especially deep ice core drilling sites, measurements were performed on large volume samples. Still, it should be noted that at North Greenland Eemian Ice Drilling (NEEM), although large volume samples were used, the data dispersion is higher than for Byrd (Fig. 4) and part of the discrepancy between the model and data may be due to the uncertainty in the data.

For our study we gathered density data covering the whole firn depth range, for which we had confidence in the data quality and the major site characteristics (temperature, accumulation). Although the effects of uncertainties on the data and natural density variability cannot be completely separated, we evaluate the data dispersion around the polynomial fit:

$\sigma_{\text {fit-data }}=\sqrt{\left[\sum_{i=1}^{N_{\max }} \frac{\left(\rho_{\text {fit }}^{i}-\rho_{\text {measured }}^{i}\right)^{2}}{N_{\max }}\right]}$,

where $N_{\max }$ is the number of steps of data points, $\rho_{\text {fit }}$ represents the regression of the density profile, and $\rho_{\text {measured }}$ is the measured density averaged on a $0.25 \mathrm{~m}$ window. $\sigma_{\text {fit-data }}$ generally lies below $10.0 \mathrm{~kg} \mathrm{~m}^{-3}$ (Fig. 5).

In order to visualize the model-data comparison with the different versions of the model at the 22 selected sites, we calculate the following deviation in parallel to the $\sigma_{\text {fit-data }}$ above (Eq. 11):

$\sigma_{\text {model-fit }}=\sqrt{\left[\sum_{i=1}^{N_{\max }} \frac{\left(\rho_{\text {model }}^{i}-\rho_{\text {fit }}^{i}\right)^{2}}{N_{\max }}\right]}$.

Note that here we compare the model to the fit of the data and not directly to data because of the strong site to site differences in the data (e.g. data resolution, sample size). Figure 5 and Table $\mathrm{S} 1$ display the $\sigma_{\text {model-fit }}$ for the 22 different sites before and after modifications detailed in Sect. 2 .

\subsubsection{Data-model comparisons using the old model}

Comparing our model results to density data is not trivial due to the diversity in measurement techniques and samplings discussed above, as well as the natural variability in density that we do not capture with a simplified model aiming at simulating very long timescales. A rough indication is given by comparing $\sigma_{\text {model-fit }}$ and $\sigma_{\text {fit-data }}$. They are of the same order of magnitude although $\sigma_{\text {fit-data }}$ is always lower than $\sigma_{\text {model-fit }}$ (Fig. 5), confirming that the old model is likely not able to fully represent the diversity of the density profiles at the 22 measurement sites.

The model-data agreement is variable among the different sites even for those with similar surface climatic conditions. The temperatures and accumulation rates at Dome $\mathrm{C}$ and Vostok being similar, model results at these sites are similar, but the density data have a clearly different shape. At Vostok, a high densification rate is observed well above the critical density of about $550 \mathrm{~kg} \mathrm{~m}^{-3}$. One possible reason is the very different flow regimes of the two sites, one being at a Dome summit, and the other on a flow line and subject to a horizontal tension (Lipenkov et al., 1989). This is not taken into account in our simplified 1-D model. Some density data at other sites also show no densification rate change near the critical density, resulting in model-data mismatches (see Siple Dome, km 105, km 200, Mizuho in Fig. S6).

The main disagreement between the old model and data is observed at the transition between the first and the second densification stages with too-high modelled densities and an associated slope change in the density profile that is too strongly imprinted. This effect is due to a densification rate that is too high in the first stage.

\subsubsection{Data-model comparisons using the new model with only one activation energy}

The modifications of the first densification stage described in Sect. 2.1 mainly reduce the slope change at the transition between the Alley (1987) and Arzt (1982) mechanisms (not shown). It also suppresses an instability of the previous model version, which could fail to find a continuous densification rate at the boundary between the Alley (1987) and Arzt (1982) mechanisms.

However, the new model still shows a tendency to overestimate the snow densification rate and then underestimate the densification rate in the firn, as shown for NEEM and Vostok in Fig. 4.

Still, looking at all different firn profiles, the general agreement between modelled and measured firn density profiles is preserved. The agreement between measured and modelled firn density is increased for some sites at (1) low accumulation rate and temperature in Antarctica (Dome A, Vostok, and Dome $\mathrm{C}$ but not South Pole) and at (2) relatively high temperature and accumulation rate (Dye 3, Siple Dome, NEEM). In parallel, a larger disagreement between model and data is observed for some other sites, particularly in coastal Antarctica (DE08, km 200, WAIS Divide). When introducing these modifications for simulating $\delta^{15} \mathrm{~N}$ evolutions over the last deglaciation, no significant changes are observed with respect to simulations run with the old LGGE model. This is not unexpected since most of the modifications concern the first stage of densification (top 10-15 $\mathrm{m}$ of the firn). The other modification concerns the LID definition. It only has a small impact on the model results for the glacial-interglacial tran- 

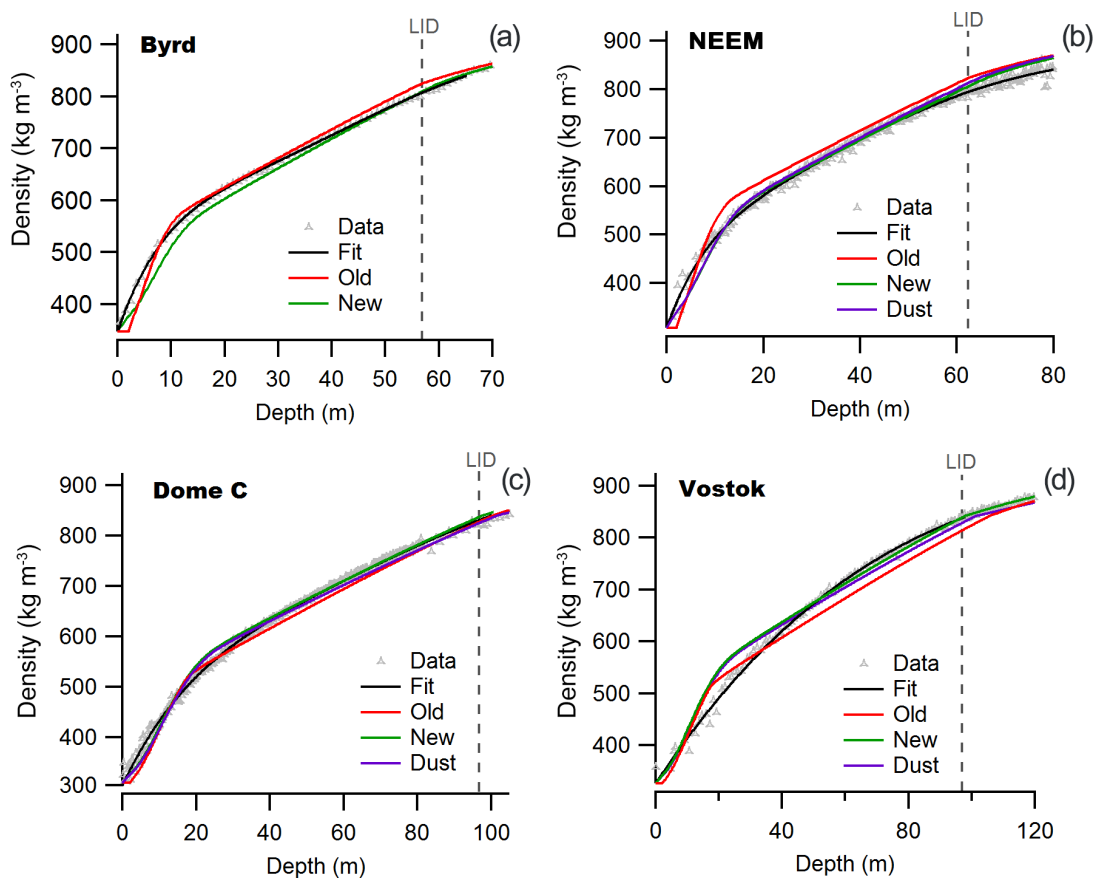

Figure 4. Density profiles of Byrd (a), NEEM (b), Dome C (c), and Vostok (d). The grey triangles correspond to the data. The black line corresponds to the polynomial fit, the red one to the old simulation, the green one to the new simulation, and the purple one to the new simulation with impurity effect.

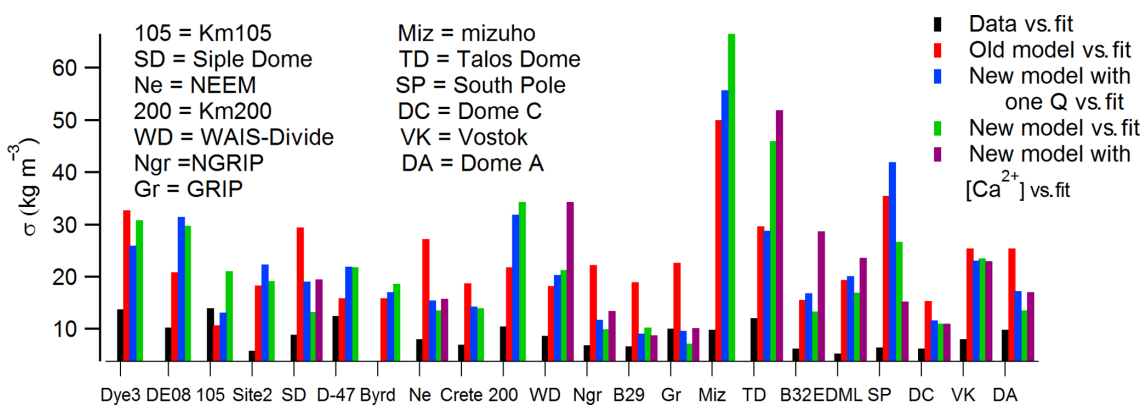

Figure 5. Representation of the $\sigma_{\text {fit-data }}$ in black and the $\sigma_{\text {model-fit }}$ (in red for the old model, in blue for the model with the new parameterization except the three activation energies, in green for the new model with three activation energy, and in purple for the new model with the impurity effect) at 22 Greenland and Antarctic sites. The site characteristics are provided in Table S1.

sitions and slightly increases the model-data mismatch over deglaciations (Fig. S7).

\subsubsection{Data-model comparisons using the new model with three activation energies and implementation of impurity effect}

The introduction of three different activation energies for different temperature ranges leads to changes in the modelled density profiles at high densities (above about $800 \mathrm{~kg} \mathrm{~m}^{-3}$ ). A clear improvement is obtained for example at South Pole (Fig. S6), although the overall impact of using three activation energies remains small.
The incorporation of the impurity effect following the Freitag et al. (2013) parameterization in our model slightly deteriorates the model-data agreement because no specific readjustment of model parameters was performed. However, the model prediction of the density profiles remains correct, although the impurity effect parameterization was developed for a different purpose, i.e. simulating density layering (Freitag et al., 2013). This encouraged us to test this simple parameterization in glacial climate conditions.

Overall, $\sigma_{\text {model-fit }}$ is only improved by $3 \%$ when using the modified model (three activation energies and implementation of impurity effect) instead of the former Goujon et al. (2003) mechanical scheme. We thus conclude that the two versions of the model perform equally well. 
Finally, it should be noted that our main purpose is to improve the agreement between the modelled LID and the evolution of $\delta^{15} \mathrm{~N}$ over deglaciations in Antarctica. Thus, in addition to the comparison of density profiles above, we compared the depths at which the LID density, as defined by Eq. (10), is reached in the polynomial fit to the data and in the new model results. In the old version of the model, the LID differences between the model and data range between $-17.9 \mathrm{~m}$ (at South Pole) and $+8.6 \mathrm{~m}$ (at km 200) with a small mean value of $-1.9 \mathrm{~m}$ and a standard deviation of $6 \mathrm{~m}$. In the new version, the LID differences between the model and data are comparable, ranging between $-14.1 \mathrm{~m}$ (at South Pole) and $+12.8 \mathrm{~m}$ (at Talos Dome) with a small mean value of $-0.7 \mathrm{~m}$ and a standard deviation of $6 \mathrm{~m}$. Similar results are obtained for $\Delta$ age (see Table S2): the agreement with the data is similar for all model versions, and most cold sites are improved with the new model. However, the $\sigma_{\text {model-fit values }}$ remain high compared to the variability in the data $\left(\sigma_{\text {fit-data }}\right.$, black bars in Fig. 5). We thus conclude from this section that the LGGE new firn densification model preserves the good agreement between (1) modelled and measured firn density profiles and (2) modelled and measured LID. We explore in the next section the performances of the new model for the coldest and driest conditions by looking at the modelled LID and hence $\delta^{15} \mathrm{~N}$ evolution over glacial-interglacial transitions.

\section{$3.2 \delta^{15} \mathrm{~N}$ glacial-interglacial profiles}

In order to test the validity of the densification model in a transient mode, we model the time evolution of $\delta^{15} \mathrm{~N}$ over the last deglaciation, and compare it to measurements at four Antarctic and Greenland deep ice core sites: Dome C (cold and low accumulation site in Antarctica with a strong mismatch observed between data and the old model), EDML (intermediate temperature and accumulation rate in Antarctica with a significant mismatch between data and the old model), WAIS Divide (high temperature and accumulation rate site in Antarctica with a good model-data agreement) and NGRIP (Greenland site with a good agreement between model and data) (Fig. 3).

The computation of $\delta^{15} \mathrm{~N}$ depends on the convective zone thickness, the LID, and the firn temperature profile. The gravitational $\delta^{15} \mathrm{~N}$ signal is indeed calculated from the LID and mean firn temperature according to the barometric equation (Eq. 1). The thermal $\delta^{15} \mathrm{~N}$ depends on the temperature gradient between the surface and the LID. A small thermal signal exists in Antarctica because of geothermal heat flux (with an average change of about $0.02 \%$ during deglaciation) but no millennial variations are expected because the temperature variations are slow $\left(<2{ }^{\circ} \mathrm{C} / 1000\right.$ years $)$ compared to abrupt climate changes observed in Greenland (e.g. NGRIP).

The model calculates the firn diffusive column height and thermal fractionation at the bottom of the firn for each ice core depth. To take into account the smoothing due to gas diffusion in the open pores and progressive bubble close-off (Schwander et al., 1993), we smooth the $\delta^{15} \mathrm{~N}$ output with a log-normal distribution, of width $\Delta$ age $/ 5$ and $\sigma=1$ (Köhler et al., 2011; Orsi et al., 2014). This formulation of the smoothing takes into account the variations in the gas-age distribution with time. Note that it has been suggested that the width in Köhler et al. (2011) is too wide. Still, using a smaller width does not modify the modelled amplitude of the $\delta^{15} \mathrm{~N}$ signal over the deglaciation so that our conclusions are not affected by such uncertainty.

\subsubsection{Input scenarios}

For the simulation of the $\delta^{15} \mathrm{~N}$ evolution over the last deglaciation, the firn densification model is forced by a scenario of surface temperature and accumulation rate deduced from ice core data (Table S3). In Greenland (NGRIP, GISP2), the temperature is reconstructed using the $\delta^{18} \mathrm{O}_{\text {ice }}$ profiles together with indication from borehole temperature measurements (Dahl-Jensen, 1998) and $\delta^{15} \mathrm{~N}$ data for NGRIP (Kindler et al., 2014) for the quantitative amplitude of abrupt temperature changes. Greenland accumulation rate is deduced from layer counting over the last deglaciation (e.g. Rasmussen et al., 2006). The uncertainty in the temperature reconstructions can be estimated to $\pm 3^{\circ} \mathrm{C}$ over the last deglaciation in Greenland (Buizert et al., 2014). As for the Greenland accumulation rate, an uncertainty of $20 \%$ can be associated with the Last Glacial Maximum (LGM) value (Cuffey and Clow, 1997; Guillevic et al., 2013; Kapsner et al., 1995). In Antarctica, both temperature and accumulation rate are deduced from water isotopic records except for WAIS Divide, where layer counting back to the last glacial period is possible (Buizert et al., 2015). Temperature uncertainty for the amplitude of the last deglaciation is estimated to be from -10 to $+30 \%$ in Antarctica (Jouzel, 2003). The reason for such asymmetry is mainly linked to outputs of atmospheric general circulation models equipped with water isotopes. These models suggest that the present-day spatial slope between $\delta^{18} \mathrm{O}$ and temperature most probably underestimates the amplitude of the temperature change between glacial and interglacial periods. We have used this estimate of asymmetric uncertainty on the amplitude of temperature change during deglaciation in our study. Recent studies have also suggested that the relationships between water isotopes and temperature and between water isotopes and accumulation rate can be applied with confidence in Antarctica for glacial temperature reconstruction (Cauquoin et al., 2015), while one should be cautious for interglacial temperature reconstruction with warmer conditions than today (Sime et al., 2009). Finally, a recent estimate of the deglacial temperature increase based on $\delta^{15} \mathrm{~N}$ measurements at WAIS (Cuffey et al., 2016) led to a $11.3^{\circ} \mathrm{C}$ temperature increase over the last deglaciation $\left(1^{\circ} \mathrm{C}\right.$ warming to be attributed to change in elevation). This is larger than the temperature increase reconstructed in East Antarctica from water isotopes by $2-4{ }^{\circ} \mathrm{C}$ and again not in favour of a warm LGM. 


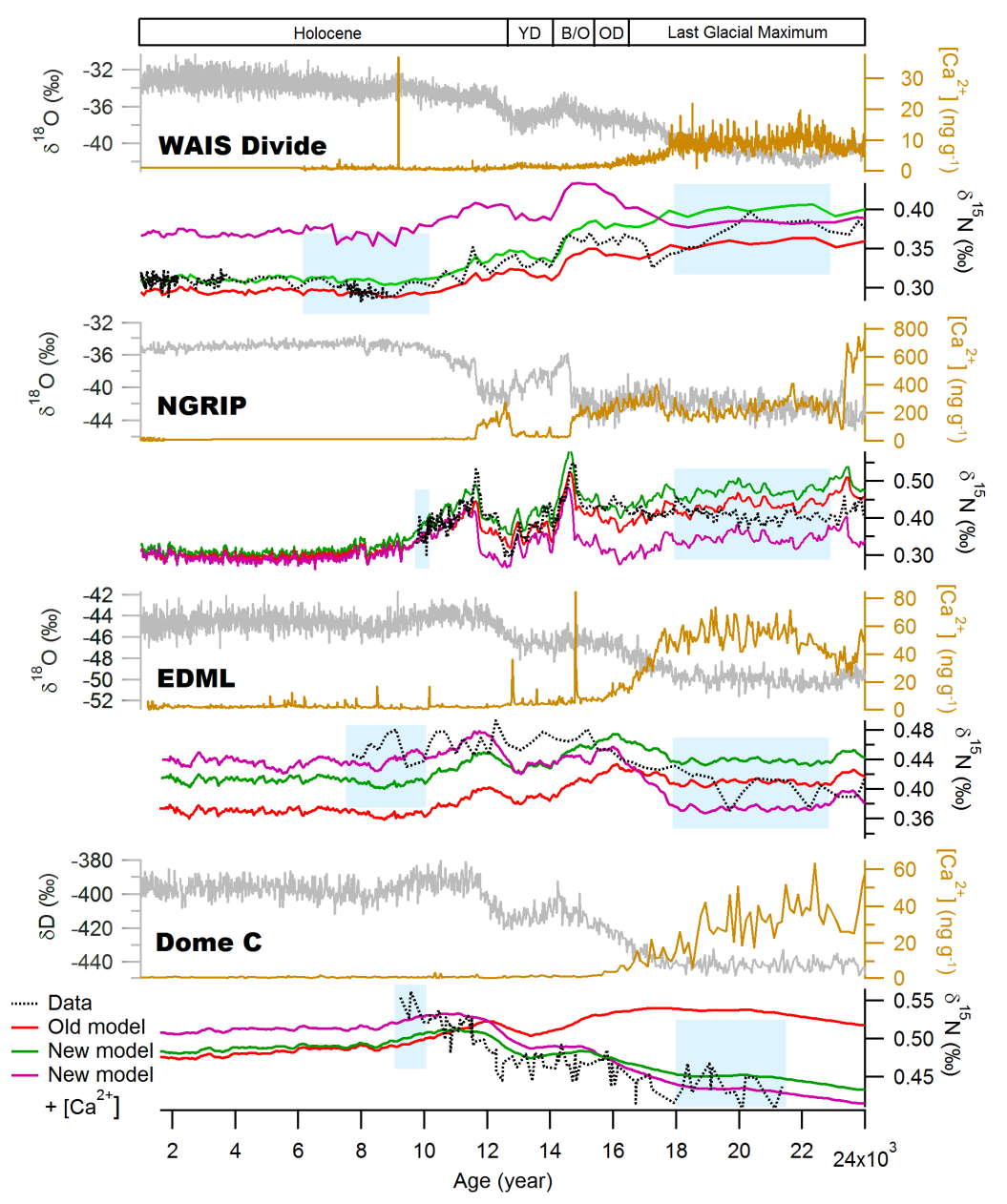

Figure 6. Comparison of the measured $\delta^{18} \mathrm{O}$ or $\delta \mathrm{D}$ (grey), the calcium concentration (gold), the measured $\delta^{15} \mathrm{~N}$ (black), and the modelled $\delta^{15} \mathrm{~N}$ (old (red), new version (green), and new version with impurity (purple)) of the LGGE model for WAIS Divide, NGRIP, EDML, and Dome C. Blue boxes for each site indicate the periods over which the $\delta^{15} \mathrm{~N}$ average for the LGM and early Holocene (EH) have been estimated for the calculation of the amplitude of the $\delta^{15} \mathrm{~N}$ change over the deglaciation.

In the construction of the AICC2012 chronology (Bazin et al., 2013; Veres et al., 2013), the first-order estimate of accumulation rate from water isotopes for EDML, Talos Dome, Vostok, and Dome $\mathrm{C}$ has been modified by incorporating dating constraints or stratigraphic tie points between ice cores (Bazin et al., 2013; Veres et al., 2013). The modification of the accumulation rate profiles over the last deglaciation for these four sites is less than $20 \%$ and the uncertainty of accumulation rate generated by the DATICE model used to build AICC 2012 from background errors (thinning history, accumulation rate, LID) and chronological constraints is $30 \%$ for the LGM (Bazin et al., 2013; Frieler et al., 2015; Veres et al., 2013). Still, it should be noted that the uncertainty of $20 \%$ on LGM accumulation rate at central sites as given in the AICC2012 construction is probably overestimated. Indeed, deglaciation occurs around $500 \mathrm{~m}$ depth at Dome C, hence with small uncertainty on the thinning function and on the accumulation rate. These values are consistent with previ- ous estimates of accumulation rate uncertainties over the last deglaciation $( \pm 10 \%$ for Dome C, Parrenin et al., 2007, and $\pm 30 \%$ in EDML, Loulergue et al., 2007).

We showed in Sect. 2.1 that surface density does not have a strong impact on the LID determination (Fig. S3). We do not have any indication of surface density in the past; thus, we impose a constant surface density of 0.35 for all sites at all times for transient runs. In order to convert the LID (deduced from density) to the $\mathrm{DCH}$ measured by $\delta^{15} \mathrm{~N}$, we need an estimate of the convective zone in the past. We use a $2 \mathrm{~m}$ convective zone for all sites, except Vostok, where we use $13 \mathrm{~m}$, in accordance with firn measurements (Bender et al., 2006). We assume that the convective zone did not evolve during the last deglaciation, consistent with dating constraints at Dome $\mathrm{C}$ and at Vostok during Termination 2 (Parrenin et al., 2012; Bazin et al., 2013; Veres et al., 2013; Landais et al., 2013). 


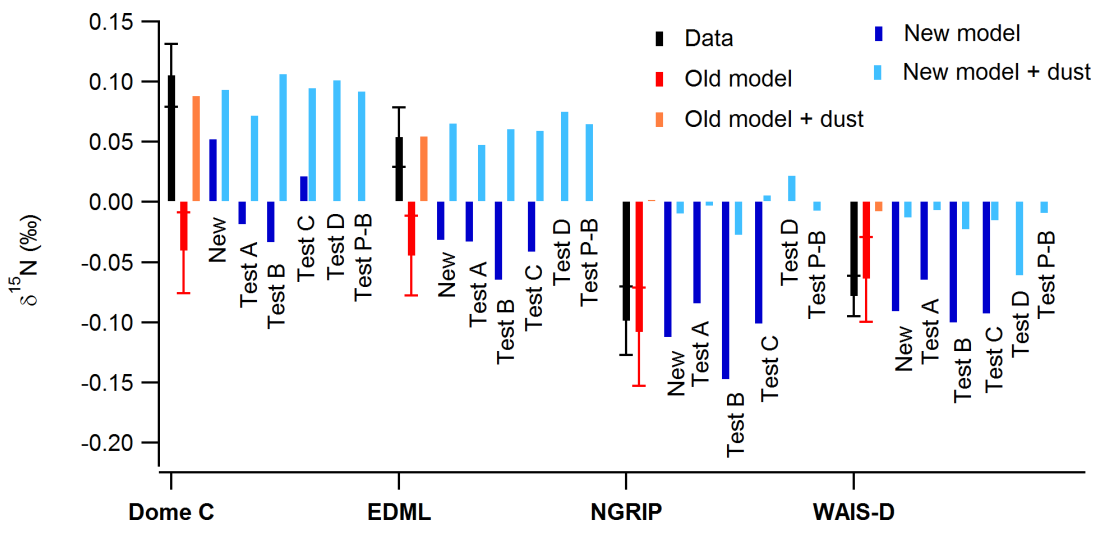

Figure 7. Difference between EH and LGM $\delta^{15} \mathrm{~N}$ at four different polar sites (raw data are given in Table S4). The measured $\delta^{15} \mathrm{~N}$ difference is shown by a black bar (data). The modelled $\delta^{15} \mathrm{~N}$ difference is shown with colours: old version in red (orange with the impurity influence), new version in blue with different parameterizations. "New" corresponds to the parameterization in Table 1. Parameterizations for sensitivity tests A, B, C, and D are given in Table 3. When "+ dust" is mentioned, it corresponds to the addition of the impurity influence as parameterized by Freitag et al. (2013) (Eqs. 8 and 9). Test Pimienta-Barnola (P-B) corresponds to a test with implementation of the impurity effect in the "New" parameterization following the Freitag parameterization adapted to the Pimienta-Barnola model instead of the Herron and Langway model used for the other sensitivity tests. We display the modelled error bars only on the old model outputs (red) but the same uncertainty can be applied to all model outputs (New; Tests A, B, C, and D; and P-B) at each site.

\subsubsection{Transient run with the old model}

In this section, we focus on the $\delta^{15} \mathrm{~N}$ evolution over the deglaciation at different Greenland and Antarctic sites as obtained from the data and as modelled with the old version of the LGGE model. This comparison serves as a prerequisite for the comparison with outputs of the revised model over the same period for the same polar sites. The comparison between the old LGGE model and $\delta^{15} \mathrm{~N}$ data over the last deglaciation shows the same patterns already discussed in Capron et al. (2013). At Greenland sites, there is an excellent agreement between model and data showing both the decrease in the mean $\delta^{15} \mathrm{~N}$ level between the LGM and the Holocene and the $\sim 0.1 \%$ peaks in $\delta^{15} \mathrm{~N}$ associated with the abrupt temperature changes (end of the Younger Dryas, Bølling-Allerød, Dansgaard-Oeschger 2, 3, and 4; Figs. 6 and S8). Conversely, the modelled and measured $\delta^{15} \mathrm{~N}$ values over the last deglaciation show significant dissimilarities in Antarctic $\delta^{15} \mathrm{~N}$ profiles displayed in Figs. 6 and S8, except at the relatively high accumulation rate and temperature site of WAIS Divide where the model properly simulates the $\delta^{15} \mathrm{~N}$ evolution in response to the change in accumulation and mean firn temperature estimated from water isotopic records and borehole temperature constraints (Buizert et al., 2015). Note that in Buizert et al. (2015), the modelled $\delta^{15} \mathrm{~N}$ was obtained from the Herron and Langway model. For the other Antarctic sites (Fig. 6), we observe that model and data disagree on the $\delta^{15} \mathrm{~N}$ difference between the LGM and Holocene levels. At EDML, Dome C, and Vostok, the model predicts a larger LID during the LGM, while $\delta^{15} \mathrm{~N}$ suggests a smaller LID compared to the Holocene (with the assumption of no change in the convective zone during the deglaciation). In addition, the measured $\delta^{15} \mathrm{~N}$ profiles at Berkner Is- land, Dome C, EDML, and Talos Dome display an additional short-term variability, i.e. $\delta^{15} \mathrm{~N}$ variations of $0.05 \%$, in a few centuries during stable climatic periods. These variations can be explained by the ice quality (coexistence of bubbles and clathrates) at Dome C and EDML. Indeed, for pure clathrate ice from these two sites, such short-term variability is not observed (e.g. Termination 2 at Dome C, Landais et al., 2013). At Berkner Island and Talos Dome, these variations cannot be explained by the quality of the measurements, by thermal effects, or by dust influence. They are also not present in the accumulation rate and temperature forcing scenarios deduced from water isotopes (Capron et al., 2013). In the absence of alternative explanations, we can thus question the existence of and variations in a convective zone and/or the accuracy of the reconstruction of past accumulation rate and temperature scenarios from water isotopes in Antarctica except at WAIS Divide where layer counting is possible over the last deglaciation. We thus further explore the influence of accumulation rate and temperature uncertainties on the $\delta^{15} \mathrm{~N}$ modelling.

The uncertainties in the changes in temperature and accumulation rates over the deglaciation significantly influence the simulated $\delta^{15} \mathrm{~N}$, as already shown in previous studies. This sensitivity of $\delta^{15} \mathrm{~N}$ has even been used to adjust temperature and/or accumulation rate scenarios (Buizert et al., 2013; Guillevic et al., 2013; Kindler et al., 2014; Landais et al., 2006). We tested the influence of the accumulation rate and temperature scenarios on the simulated $\delta^{15} \mathrm{~N}$ profiles for the last deglaciation, but even with large uncertainties in the input scenarios, it is not possible to reproduce the measured Antarctic $\delta^{15} \mathrm{~N}$ increase at Dome $\mathrm{C}$ and EDML with the old version of the LGGE model. 
This result is illustrated in Fig. 7 in which we display a comparison between the amplitude of the measured $\delta^{15} \mathrm{~N}$ change and the amplitude of the modelled $\delta^{15} \mathrm{~N}$ change with the Goujon version over the last deglaciation. For this comparison, we calculated the Last Glacial Maximum (LGM) $\delta^{15} \mathrm{~N}$ average between 18 and $23 \mathrm{kyr}$ and the early Holocene (EH) $\delta^{15} \mathrm{~N}$ average between 6 and $10 \mathrm{kyr}$ (or smaller, depending on available data; see blue boxes in Fig. 6). We estimated the uncertainty in the measured $\delta^{15} \mathrm{~N}$ change by calculating first the standard deviation of the $\delta^{15} \mathrm{~N}$ data over each of the two periods, LGM and EH, as $\sigma_{15} \mathrm{~N}_{\mathrm{N}} \mathrm{data} \mathrm{EH}$ and $\sigma_{15} \mathrm{~N} \_$data_LGM and then the resulting uncertainty in the $\delta^{15} \mathrm{~N}$

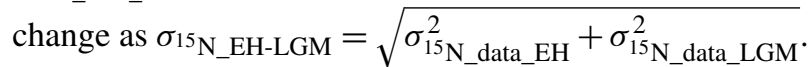

As for the modelled $\delta^{15} \mathrm{~N}$ change, associated error bars are deduced from the uncertainty in the temperature and accumulation input scenarios (shown in Fig. S9 for the improved model). The total error bar hence shows the difference between most extreme accumulation rate or temperature input scenarios. In these sensitivity tests, we assumed that it is not possible to have an underestimation of the temperature change while at the same time having an overestimation of the accumulation rate (or the opposite) because changes in accumulation rate and temperature are linked, at least qualitatively when comparing LGM and Holocene mean values.

\subsubsection{Results with updated temperature parameterization}

By construction, the new LGGE firn model with the temperature dependency of the firn densification module described in Sect. 2.2.1 is expected to improve the agreement between model and data for cold sites in East Antarctica over the last deglaciation by increasing densification rates at low temperature. This new parameterization modifies the densification rate through the creep parameter given in Eq. (7). Figure 8 shows the evolution of the creep parameter with temperature for different choices of the three activation energies $Q_{1}, Q_{2}$, and $Q_{3}$. Compared to the old model, the densification rate is higher at low temperature, below $-55^{\circ} \mathrm{C}$ (i.e. for LGM at Dome $\mathrm{C}$ and Vostok, Table 1). At higher temperature (between -55 and $-28{ }^{\circ} \mathrm{C}$ corresponding to present-day temperature at most polar sites), the creep parameter is slightly lower than in the old model. The difference between the two curves is however not large so that densification rate is not strongly modified over this range. This is in agreement with comparable firn density profiles obtained for the different polar sites using the old or the improved LGGE model (Sect. 3.1, Fig. 4).

In the improved model, the simulated profiles of $\delta^{15} \mathrm{~N}$ are comparable to $\delta^{15} \mathrm{~N}$ simulated with the old model at the sites that already showed a good agreement between the old model outputs and data, for example NGRIP, GISP-2, Talos Dome, and WAIS Divide (Figs. 6 and S8). This is expected since the corresponding densification rate is only slightly reduced
Table 2. Values used for the different sensitivity tests for three activation energies. These values have been chosen to illustrate the effects of varying activation energies for the different temperature ranges on the densification rate for the different ice core deep drilling sites (see Fig. 8) and to support the tuning presented in Table 1 .

\begin{tabular}{lll}
\hline Test & Activation energy $\left(\mathrm{J} \mathrm{mol}^{-1}\right)$ & Coefficient \\
\hline Test A & $Q_{1}=90000$ & $a_{1}=5.5 \times 10^{5}$ \\
& $Q_{2}=60000$ & $a_{2}=1.0$ \\
& $Q_{3}=30000$ & $a_{3}=4.5 \times 10^{-8}$ \\
\hline Test B & $Q_{1}=110000$ & $a_{1}=5.5 \times 10^{9}$ \\
& $Q_{2}=75000$ & $a_{2}=1950.0$ \\
& $Q_{3}=1500$ & $a_{3}=9.0 \times 10^{-16}$ \\
\hline Test C & $Q_{1}=110000$ & $a_{1}=1.05 \times 10^{9}$ \\
& $Q_{2}=75000$ & $a_{2}=1400$ \\
& $Q_{3}=15000$ & $a_{3}=8.7 \times 10^{-12}$ \\
\hline Test D & $Q_{1}=110000$ & $a_{1}=1.05 \times 10^{9}$ \\
& $Q_{2}=75000$ & $a_{2}=980$ \\
& $Q_{3}=1230$ & $a_{3}=3.6 \times 10^{-15}$ \\
\hline
\end{tabular}

in the temperature range from $-55^{\circ} \mathrm{C}$ to $-28^{\circ} \mathrm{C}$, which corresponds to the temperature range encompassed over the last deglaciation at these sites. This results in a deeper LID and hence higher $\delta^{15} \mathrm{~N}$ level, which is in general compatible with the data (except at Talos Dome). Some differences are also observed for the timing of the $\delta^{15} \mathrm{~N}$ peaks for BøllingAllerød and the end of the Younger Dryas at NGRIP when using the different model versions, reflecting variations in the simulated $\Delta$ age (see Table S5); the general agreement with the measured profile is preserved with even a slight improvement of the modelled $\Delta$ age with $\delta^{15} \mathrm{~N}$ constraints with the modified model. At the coldest sites (Dome C, Vostok), the agreement between data and modelled profiles is largely improved with a modelled LGM $\delta^{15} \mathrm{~N}$ smaller than the modelled EH $\delta^{15} \mathrm{~N}$, but a perfect match cannot be found. At the intermediate EDML site, it is not possible to reproduce the sign of the slope during the deglaciation.

In order to more quantitatively assess the robustness of the proposed parameterization in Table 1, we confront in Fig. 7 the measured and modelled $\delta^{15} \mathrm{~N}$ differences between the LGM and EH at the four Greenland and Antarctic sites selected in Fig. 7 above. For this comparison, we use not only the parameterization of Table 1 but also sensitivity tests performed with different parameterizations of the temperature dependency of activation energy and impurity effects (details in Table 2).

When using the parameterization in Table 1 (new model), Fig. 7 shows strong improvement of the simulation of the $\delta^{15} \mathrm{~N}$ difference between EH and LGM at Vostok and Dome C. Indeed, the modelled EH-LGM difference now has 


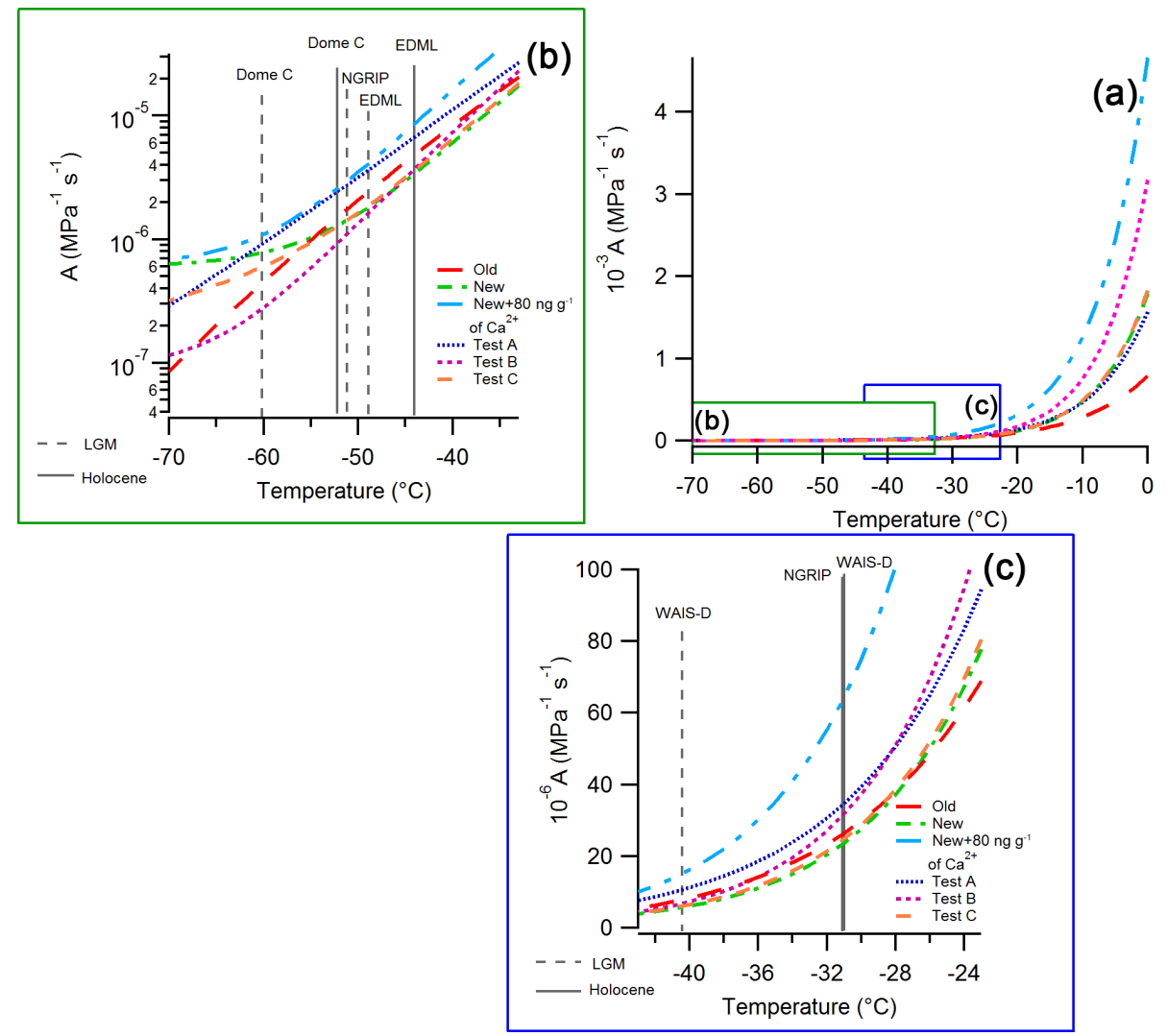

Figure 8. Dependence of the creep parameter (Eq. 7) as a function of temperature for six different parameterizations. "Old" corresponds to the Goujon et al. (2003) version of the model; "New" corresponds to the improved LGGE model with parameterization described in Table 1; "New $+80 \mathrm{ng} \mathrm{g}^{-1}$ of $\mathrm{Ca}^{2+}$ " corresponds to the parameterization of Table 1 with the addition of the impurity effect following Eq. (8) and a $\left[\mathrm{Ca}^{2+}\right]$ value of $80 \mathrm{ng} \mathrm{g}^{-1}$; tests $\mathrm{A}, \mathrm{B}$, and $\mathrm{C}$ are sensitivity tests run with the values presented in Table 3 . Panel (a) shows the creep parameter evolution for the whole temperature range, $(\mathbf{b})$ is a focus at very low temperature, and (c) is a focus at intermediate temperature. The grey vertical lines indicate the temperature for the early Holocene (EH, solid line) and LGM (dotted line) at the four study sites presented in Figs. 6 and 7.

the correct sign at very cold sites in East Antarctica (Fig. 7) when compared with $\delta^{15} \mathrm{~N}$ measurements.

We present some sensitivity tests to illustrate the choice of our final parameterization (i.e. the new model) through influences on the creep parameters and LGM vs. EH $\delta^{15} \mathrm{~N}$ changes. As displayed in Fig. 8, test A has a higher creep parameter than the old model throughout the whole temperature range. Compared to the output of the old model, the LGM vs. EH $\delta^{15} \mathrm{~N}$ change simulated with test A is slightly higher but the sign of the $\delta^{15} \mathrm{~N}$ change over the last deglaciation is still wrong at Dome C and EDML. This test shows that it is not the mean value of the creep parameter that needs to be changed, but the dependency on temperature. Test $\mathrm{B}$ has a higher creep parameter above $-35^{\circ} \mathrm{C}$, but a lower creep parameter than the old model below $-35^{\circ} \mathrm{C}$, which starts flattening and hence reaching values higher than the old model creep parameter below $-65^{\circ} \mathrm{C}$. The LGM vs. EH $\delta^{15} \mathrm{~N}$ change simulated with test $\mathrm{B}$ is still comparable with data at WAIS Divide. However, the model-data comparison deteriorates at NGRIP and EDML compared to the model- data comparison with the old version of the model. Moreover, it does not solve the model-data mismatch at Dome C. This shows that the change in the creep parameter at intermediate temperature is too steep. Strong differences occur at high temperature (above $-30^{\circ} \mathrm{C}$ ) but it does not affect the modelled $\delta^{15} \mathrm{~N}$ change between LGM and EH for our four sites. On the contrary, the slightly lower creep parameter at low temperature leads to a worse agreement between model and data for the Dome $\mathrm{C}$ deglaciation than when using the new model. Test $\mathrm{C}$ has been designed so that the activation energy at low temperature corresponds to estimates of activation energy for ice surface diffusion (Jung et al., 2004; Nie et al., 2009), a mechanism that is expected to be important at low temperature (Ashby, 1974). Using such a parameterization leads to a fair agreement between the modelled and the measured $\delta^{15} \mathrm{~N}$ change over the last deglaciation for the different sites. At Dome C, the correct sign for the $\delta^{15} \mathrm{~N}$ evolution between LGM and the Holocene is predicted by the model. However, the modelled $\delta^{15} \mathrm{~N}$ increase is still too small compared to the data and the $\delta^{15} \mathrm{~N}$ calculated by the new model. 
This is probably due to a too-high creep parameter at low temperature.

Summarizing, the best agreement between data and model for Dome $\mathrm{C}$ is obtained for the parameters given in Table 1: the creep parameter of the new model flattens below $-50^{\circ} \mathrm{C}$ and is thus not very different for the LGM or the EH at Dome C. As a result, the modelled LID and hence $\delta^{15} \mathrm{~N}$ values are less sensitive to temperature, and the sign of the EH-LGM difference can be inverted and brought closer to the observations. It should be noted that despite many sensitivity tests we could not find a parameterization able to reproduce the EH-LGM $\delta^{15} \mathrm{~N}$ changes for all four sites. In the new model without impurity effect, it is not possible to reproduce the measured EDML $\delta^{15} \mathrm{~N}$ change over the last deglaciation even when taking into account the uncertainty in the input parameters (temperature and accumulation rate, Fig. S9).

\subsubsection{Impurity softening}

The dust content in LGM ice is much larger than in Holocene ice (Fig. 6), and impurity inclusions in ice have an impact on the grain structure, allowing it to deform more easily (Alley, 1987; Fujita et al., 2014). We incorporated dust softening using the parameterization of Freitag et al. (2013) as detailed in Sect. 2.2.2. We compared two expressions for the impurity softening (tuned to be applied to the Herron and Langway model, or Pimienta and Barnola model), but found that the differences between the two parameterizations were minor (Fig. 7). We use the Herron and Langway parameters in the following.

Figure 8 shows the effect of impurities on the creep parameter: densification is enhanced over the whole temperature range. At all sites, incorporating impurity softening reduces the firn thickness during periods characterized by high impurity concentration in the ice (LGM). It thus leads to an increase in the EH-LGM LID difference (Fig. 7).

This effect clearly helps to bring into agreement modelled and measured $\delta^{15} \mathrm{~N}$ at Dome C, Vostok, and EDML (Figs. 6, 7, and S8). The improvement through dust softening is particularly important at EDML where the change of activation energy had only a modest effect. For the three sites mentioned above, the model incorporating the parameterization of activation energy depicted in Table 1 and the impurity effects are able to reproduce the $\delta^{15} \mathrm{~N}$ increase over the last deglaciation. Note that short-lived peaks in impurities, likely triggered by volcanic events, have no visible effect on bulk firn thickness (Fig. 6). Contrary to the improved situation at cold Antarctic sites, we observe that, at the warmer sites like NGRIP and WAIS Divide, incorporating impurity softening deteriorates the model data fit, which was already good in the older version of the model and also good with other firn densification models (Kindler et al., 2014; Buizert et al., 2015). Incorporation of impurity softening also produces almost no change in firn thickness between the LGM and the EH at NGRIP, which contradicts $\delta^{15} \mathrm{~N}$ observations. The same mismatch is observed at WAIS Divide using a different model, as already noted by Buizert et al. (2015). We tested the sensitivity to the dust parameterization by implementing the Freitag parameterization adapted to the Pimienta-Barnola model instead of the parameters for the Herron and Langway model used with our improved model (see Sect. 2.2.2). The two different parameterizations of the impurity effect lead to very comparable LGM to EH $\delta^{15} \mathrm{~N}$ changes over the last deglaciation at the four sites discussed here.

The model-data mismatch observed when incorporating the dust effect may be partially due to the fact that we did not readjust $a_{i}$ and $Q_{i}$ after implementation of the impurity effect. To explore this possibility, sensitivity test $\mathrm{D}$ has been designed with a re-parameterization of the $a_{i}$ and $Q_{i}$ values after implementation of the impurity effect. To do so, we calculated the optimal creep parameter A for each mean EH and LGM condition at each site and sequentially adjusted $a_{3}, a_{2}$, $a_{1}, Q_{3}, Q_{2}$, and $Q_{1}$ to minimize the model-data mismatch. Only $a_{3}, a_{2}$, and $Q_{3}$ needed adjustments, and their values can be found in Table 3. We did not perform the adjustment on modern density profiles because these are only weakly sensitive to the dust parameterization, $\mathrm{Ca}^{2+}$ concentrations being low.

Impurity concentration is very high at NGRIP during the glacial period. As a consequence, even if our new parameterization of $a_{i}$ and $Q_{i}$ (new model) properly reproduces the Greenland $\delta^{15} \mathrm{~N}$ level at the LGM, this glacial modelled Greenland $\delta^{15} \mathrm{~N}$ level is too low when including the impurity effect. The re-parameterization of $a_{i}$ and $Q_{i}$, proposed as sensitivity test $\mathrm{D}$, enables an improvement of the agreement between model and data for glacial $\delta^{15} \mathrm{~N}$ at WAIS Divide, maintaining the results at Dome-C and EDML, but can still not produce reasonable results at NGRIP (Fig. 7).

The mismatch observed for the $\delta^{15} \mathrm{~N}$ simulations at WAIS Divide and NGRIP when incorporating the impurity effect suggests that the parameterization presented in Eqs. (8) and (9) is not appropriate to be used on bulk $\left[\mathrm{Ca}^{2+}\right]$ concentration and/or for LGM simulation. Actually, the proposed parameterization by Freitag et al. (2013) was tuned to density variability in present-day firn and may not be valid for LGM when $\left[\mathrm{Ca}^{2+}\right]$ concentrations were $10-100$ times larger than present day. It is also possible that the dust effect saturates at high concentration and is no longer sensitive above a certain threshold. To further improve the model-data agreement with the dust parameterization, a possibility is to add simple thresholds on a minimum and maximum effect of calcium as proposed in the Supplement (Text S2 and Fig. S10). Implementing threshold values on calcium reduces the largest inconsistencies between model results and $\delta^{15} \mathrm{~N}$ data, in particular at NGRIP (through the threshold at high calcium concentration) and at WAIS (through the threshold at low calcium concentration).

It is also possible that the impurity influence, like temperature, acts differently depending on the dominant mechanism for firn deformation, and that the impurity effect is more 
important at colder temperature. The mechanisms by which impurities influence firn deformation are still poorly understood. Dust particles do not always influence densification in the same way: dissolved particles soften firn and ice while the softening or hardening effect of non-dissolved impurities is less clear (Fujita et al., 2016; Alley, 1987). More work is thus needed before the correct impurity effect component and the mechanisms by which it acts on densification are identified (e.g. Fujita et al., 2014, 2016). Here, we have shown that a simple parameterization as a function of $\left[\mathrm{Ca}^{2+}\right]$ concentration does not provide uniformly good results and seems only suitable for sites on the Antarctic Plateau.

To sum up, the new parameterization of the creep parameter has been designed to preserve good agreement between the old model outputs and data at sites that were already well simulated (WAIS Divide, NGRIP, Talos Dome). In addition, this parameterization improves the simulation of the deglaciation at cold Antarctic sites (Dome C, Vostok). However, the EH-LGM $\delta^{15} \mathrm{~N}$ change at Dome $\mathrm{C}$ and EDML cannot be reproduced using only the temperature dependency of activation energy. The inclusion of impurity effect following the Freitag parameterization improves the situation for cold sites but leads to inconsistent $\delta^{15} \mathrm{~N}$ evolutions over the deglaciation at WAIS Divide and NGRIP unless threshold effects are implemented.

\section{Conclusion and perspectives}

In this study, we have presented a revision of the LGGE firn densification model. We have summarized the parameterization choices of this firn model that would explain a large part of the disagreement between modelled and measured $\delta^{15} \mathrm{~N}$ evolution over the last deglaciation for extremely cold sites in East Antarctica. Based on analogy with ceramic sintering at hot temperature and recent observations of the impurity effect on firn density, we have improved the LGGE densification model by incorporating new parameterizations for the evolution of the creep parameter with temperature and impurity contents within the firn densification module. We follow previous studies evidencing different dominant firn sintering mechanisms for different temperature ranges that support a temperature dependency of the creep activation energy. We showed that these new parameterizations improve the agreement between model and data at low temperature (below $-30{ }^{\circ} \mathrm{C}$ ) and retain the good agreement at warmer temperature. In particular, the improved LGGE firn density model is now able to reproduce the $\delta^{15} \mathrm{~N}$ increase over deglaciations at cold sites such as Dome $\mathrm{C}$ and Vostok.

The new parameterization implies a more rapid firn densification at lower temperature and high impurity load than in classical firnification models. This result obtained with our associated appropriate parameterization is in agreement with the study of Parrenin et al. (2012) showing that the classical firn densification model overestimates LID during the last glacial period at EDC. With our revised model, the simulated $\Delta$ age is also significantly decreased for the glacial periods at low accumulation and temperature sites on the East Antarctic plateau (Dome C, Vostok, and Dome Fuji). This has important consequences for building air vs. ice timescales in Antarctica and hence for the studies of the relationships between temporal evolutions of atmospheric composition vs. Antarctic temperature. At EDC $21 \mathrm{ka}$ (ice age), the modelled $\triangle$ age decreases from 4840 years (old model) to 4270 years (new model) or 4200 years (new model including impurity effect). At Vostok $21 \mathrm{ka}$ (ice age), the modelled $\Delta$ age decreases from 5630 years (old model) to 5030 years (new model) or 4900 years (new model including impurity effect). The latest results are in good agreement with the recent determination of $\triangle$ age within the AICC2012 timescale: 3920 years for EDC 21 ka (ice age) and 5100 years for Vostok $21 \mathrm{ka}$ (ice age). This is not unexpected since the EDC LID in the construction of the AICC2012 timescale is deduced from the EDC $\delta^{15} \mathrm{~N}$ scenario, a hypothesis supported by the available gas and ice stratigraphic markers over the last deglaciation (Parrenin et al., 2012).

Our finding is, however, associated with several limitations so that this new model does not propose a definite reevaluation of the formulation of the activation energy but proposes some ways to be further tested and explored to improve firn densification models, especially for applications in paleoclimate reconstructions. Our approach remains empirical and we could not separately identify the different mechanisms involved. The problem of a $\delta^{15} \mathrm{~N}$ data-model mismatch at low temperature and accumulation rate sites in East Antarctica is thus not definitively solved. Still, we showed that revising the temperature and impurity dependence of firn densification rate can potentially strongly reduce the $\delta^{15} \mathrm{~N}$ data-model mismatch and proposed preliminary parameterizations are easy to implement in any firn densification model.

Finally, the new parameterization proposed here calls for further studies. First, laboratory or field studies of firn densification at very cold controlled conditions are needed to check the predominance of one mechanism over another at low temperature, such as the predominance of the boundary diffusion over grain boundary mechanism around $-60^{\circ} \mathrm{C}$; this is a real challenge because of the slow speed of deformation. Second, we have suggested that the current parameterization of impurity on firn softening should be revised, especially for very high impurity load (Greenland), using for example thresholds on impurity concentrations. Third, the separate effects of impurities and temperature on firn densification and hence $\delta^{15} \mathrm{~N}$ evolution should be tested on periods other than the last deglaciation. Sequences of events associated with non-synchronous changes in surface temperature, accumulation rate, and impurity content would be particularly valuable for this objective. Finally, additional constraints on the firn modelling can also be obtained through the use of cross-dating with high-resolution signals on new ice cores as already used by Parrenin et al. (2012). 
Data availability. The data set for all the density profiles used in this paper (presented in Fig. S6 and Table S1) can be found in the Supplement.

\section{The Supplement related to this article is available online at https://doi.org/10.5194/cp-13-833-2017-supplement.}

Competing interests. The authors declare that they have no conflict of interest.

Acknowledgements. We thank Anders Svensson, Rob Arthern, Hans Christian Steen-Larsen, and Xiao Cunde for data sharing and Sarah Guilbaud for her work during her final internship study. Thanks to Pierre Badel, Maurine Montagnat, and Christophe Martin for insightful discussions about densification mechanisms. Thanks to Myriam Guillevic for her work on the densification model and helpful discussions. This work is supported by INSU/CNRS LEFE project NEVE-CLIMAT and the ERC COMBINISO 306045.

Edited by: Hubertus Fischer

Reviewed by: two anonymous referees

\section{References}

Alley, R. B.: Firn densification by grain-boundary sliding: a first model, J. Phys. Colloq., 48, C1-249-C1-256, https://doi.org/10.1051/jphyscol:1987135, 1987.

Altnau, S., Schlosser, E., Isaksson, E., and Divine, D.: Climatic signals from 76 shallow firn cores in Dronning Maud Land, East Antarctica, The Cryosphere, 9, 925-944, https://doi.org/10.5194/tc-9-925-2015, 2015.

Anderson, D. L. and Benson, C. S.: The densification and diagenesis of snow, in Ice and Snow: Properties, Processes and Applications, pp. 391-411, MIT Press., 1963.

Arnaud, L.: Modélisation de la transformation de la neige en glace à la surface des calottes polaires; Etude du transport des gaz dans ces milieux poreux, PhD Thesis, Université Joseph Fournier Grenoble 1, 294 pp., 1997.

Arnaud, L., Barnola, J. M., and Duval, P.: Physical modeling of the densification of snow/firn and ice in, Phys. Ice Core Rec., 26, 39-44, 2000.

Arthern, R. J., Vaughan, D. G., Rankin, A. M., Mulvaney, R., and Thomas, E. R.: In situ measurements of Antarctic snow compaction compared with predictions of models, J. Geophys. Res., 115, F03011, https://doi.org/10.1029/2009JF001306, 2010.

Arzt, E.: The influence of an increasing particle coordination on the densification of spherical powders, Acta Metall., 30, 1883-1890, 1982.

Arzt, E., Ashby, M. F., and Easterling, K. E.: Practical applications of hot-isostatic pressing diagrams: four case studies, Metall. Trans. A, 14, 211-221, 1983.

Ashby, M. F.: A first report on sintering diagrams, Acta Metall. Mater., 22, 275-289, 1974.
Barnes, P., Tabor, D., and Walker, J. C. F.: The friction and creep of polycrystalline ice, P. Roy. Soc. Lond. A, 324, 127-155, 1971.

Barnola, J.-M., Pimienta, P., Raynaud, D., and Korotkevich, Y. S.: $\mathrm{CO}_{2}$-climate relationship as deduced from the Vostok ice core: a re-examination based on new measurements and on a reevaluation of the air dating, Tellus B, 43, 83-90, 1991.

Bazin, L., Landais, A., Lemieux-Dudon, B., Toyé Mahamadou Kele, H., Veres, D., Parrenin, F., Martinerie, P., Ritz, C., Capron, E., Lipenkov, V., Loutre, M.-F., Raynaud, D., Vinther, B., Svensson, A., Rasmussen, S. O., Severi, M., Blunier, T., Leuenberger, M., Fischer, H., Masson-Delmotte, V., Chappellaz, J., and Wolff, E.: An optimized multi-proxy, multi-site Antarctic ice and gas orbital chronology (AICC2012): 120-800 ka, Clim. Past, 9, 17151731, https://doi.org/10.5194/cp-9-1715-2013, 2013.

Bender M. L., Sowers T., Barnola J.-M., and Chappellaz, J.: Changes in the $\mathrm{O}_{2} / \mathrm{N}_{2}$ ratio of the atmosphere during recent decades reflected in the composition of air in the firn at Vostok Station, Antarctica, Geophys. Res. Lett., 21, 189-192, 1994.

Bender, M. L., Floch, G., Chappellaz, J., Suwa, M., Barnola, J.-M., Blunier, T., Dreyfus, G., Jouzel, J., and Parrenin, F.: Gas age-ice age differences and the chronology of the Vostok ice core, 0-100 ka, J. Geophys. Res., 111, D21115, https://doi.org/10.1029/2005JD006488, 2006.

Benson, C. S.: Stratigraphic studies in the snow and firn of the Greenland ice sheet, PhD Thesis, California Institute of Technology, 228 pp., 1960.

Blackford, J. R.: Sintering and microstructure of ice: a review, J. Phys. Appl. Phys., 40, R355-R385, https://doi.org/10.1088/0022-3727/40/21/R02, 2007.

Buizert, C., Sowers, T., and Blunier, T.: Assessment of diffusive isotopic fractionation in polar firn, and application to ice core trace gas records, Earth Planet. Sc. Lett., 361, 110-119, https://doi.org/10.1016/j.eps1.2012.11.039, 2013.

Buizert, C., Gkinis, V., Severinghaus, J. P., He, F., Lecavalier, B. S., Kindler, P., Leuenberger, M., Carlson, A. E., Vinther, B., Masson-Delmotte, V., White, J. W. C., Liu, Z., Otto-Bliesner, B., and Brook, E. J.: Greenland temperature response to climate forcing during the last deglaciation, Science, 345, 1177-1180, https://doi.org/10.1126/science.1254961, 2014.

Buizert, C., Cuffey, K. M., Severinghaus, J. P., Baggenstos, D., Fudge, T. J., Steig, E. J., Markle, B. R., Winstrup, M., Rhodes, R. H., Brook, E. J., Sowers, T. A., Clow, G. D., Cheng, H., Edwards, R. L., Sigl, M., McConnell, J. R., and Taylor, K. C.: The WAIS Divide deep ice core WD2014 chronology - Part 1: Methane synchronization (68-31 ka BP) and the gas age-ice age difference, Clim. Past, 11, 153-173, https://doi.org/10.5194/cp11-153-2015, 2015.

Caillon N., Severinghaus J. P., Jouzel J., Barnola J.-M., Kang J., and Lipenkov V. Y.: Timing of Atmospheric $\mathrm{CO}_{2}$ and Antarctic Temperature Changes Across Termination III, Science, 299, 1728-1731, 2003.

Capron, E., Landais, A., Buiron, D., Cauquoin, A., Chappellaz, J., Debret, M., Jouzel, J., Leuenberger, M., Martinerie, P., MassonDelmotte, V., Mulvaney, R., Parrenin, F., and Prié, F.: Glacialinterglacial dynamics of Antarctic firn columns: comparison between simulations and ice core air- $\delta^{15} \mathrm{~N}$ measurements, Clim. Past, 9, 983-999, https://doi.org/10.5194/cp-9-983-2013, 2013.

Cauquoin, A., Landais, A., Raisbeck, G. M., Jouzel, J., Bazin, L., Kageyama, M., Peterschmitt, J.-Y., Werner, M., Bard, 
E., and Team, A.: Comparing past accumulation rate reconstructions in East Antarctic ice cores using ${ }^{10} \mathrm{Be}$, water isotopes and CMIP5-PMIP3 models, Clim. Past, 11, 355-367, https://doi.org/10.5194/cp-11-355-2015, 2015.

Colbeck, S. C.: Theory of metamorphism of dry snow, J. Geophys. Res.-Oceans, 88, 5475-5482, 1983.

Craig, H., Horibe, Y., and Sowers, T.: Gravitational separation of gases and isotopes in polar ice caps, Science, 242, 1675-1678, 1988.

Cuffey, K. M. and Clow, G. D.: Temperature, accumulation, and ice sheet elevation in central Greenland through the last deglacial transition, J. Geophys. Res.-Oceans, 102, 26383-26396, 1997.

Cuffey, K. M., Clow, G. D., Steig, E. J., Buizert, C., Fudge, T. J., Koutnik, M., Waddington E. D., Alley, R. B., and Severinghaus, J. P., Deglacial temperature history of West Antarctica, P. Natl. Acad. Sci. USA, 11, 14249-14254, 2016.

Dahl-Jensen, D.: Past Temperatures Directly from the Greenland Ice Sheet, Science, 282, 268-271, https://doi.org/10.1126/science.282.5387.268, 1998.

Dee, D. P., Uppala, S. M., Simmons, A. J., Berrisford, P., Poli, P., Kobayashi, S., Andrae, U., Balmaseda, M. A., Balsamo, G., Bauer, P., Bechtold, P., Beljaars, A. C. M., van de Berg, L., Bidlot, J., Bormann, N., Delsol, C., Dragani, R., Fuentes, M., Geer, A. J., Haimberger, L., Healy, S. B., Hersbach, H., Hólm, E. V., Isaksen, L., Kållberg, P., Köhler, M., Matricardi, M., McNally, A. P., Monge-Sanz, B. M., Morcrette, J.-J., Park, B.-K., Peubey, C., de Rosnay, P., Tavolato, C., Thépaut, J.-N., and Vitart, F.: The ERA-Interim reanalysis: configuration and performance of the data assimilation system, Q. J. Roy. Meteor. Soc., 137, 553-597, https://doi.org/10.1002/qj.828, 2011.

Dreyfus, G. B., Jouzel, J., Bender, M. L., Landais, A., MassonDelmotte, V., and Leuenberger, M.: Firn processes and $\delta^{15} \mathrm{~N}$ : potential for a gas-phase climate proxy, Quaternary Sci. Rev., 29, 28-42, https://doi.org/10.1016/j.quascirev.2009.10.012, 2010.

Ebinuma, T. and Maeno, N.: Particle rearrangement and dislocation creep in a snow-densification process, J. Phys. Colloq., 48, C1263-C1-269, https://doi.org/10.1051/jphyscol:1987137, 1987.

EPICA community members: Eight glacial cycles from an Antarctic ice core, Nature, 429, 623-628, 2004.

Freitag, J., Kipfstuhl, S., Laepple, T., and Wilhelms, F.: Impurity-controlled densification: a new model for stratified polar firn, J. Glaciol., 59, 1163-1169, https://doi.org/10.3189/2013JoG13J042, 2013.

Frieler, K., Clark, P. U., He, F., Buizert, C., Reese, R., Ligtenberg, S. R. M., van den Broeke, M. R., Winkelmann, R., and Levermann, A.: Consistent evidence of increasing Antarctic accumulation with warming, Nat. Clim. Change, 5, 348-352, https://doi.org/10.1038/nclimate2574, 2015.

Fudge, T. J., Markle, B. R., Cuffey, K. M., Buizert, C., Taylor, K. C., Steig, E. J., Waddington, E. D., Conway, H., and Koutnik, M.: Variable relationship between accumulation and temperature in West Antarctica for the past 31000 years: wde temperature and accumulation, Geophys. Res. Lett., 43, 3795-3803, https://doi.org/10.1002/2016GL068356, 2016.

Fujita, S., Hirabayashi, M., Goto-Azuma, K., Dallmayr, R., Satow, K., Zheng, J., and Dahl-Jensen, D.: Densification of layered firn of the ice sheet at NEEM, Greenland, J. Glaciol., 60, 905-921, https://doi.org/10.3189/2014JoG14J006, 2014.
Fujita, S., Goto-Azuma, K., Hirabayashi, M., Hori, A., Iizuka, Y., Motizuki, Y., Motoyama, H., and Takahashi, K.: Densification of layered firn in the ice sheet at Dome Fuji, Antarctica, J. Glaciol., 62, 103-123, https://doi.org/10.1017/jog.2016.16, 2016.

Goujon, C., Barnola, J.-M., and Ritz, C.: Modeling the densification of polar firn including heat diffusion: Application to close-off characteristics and gas isotopic fractionation for Antarctica and Greenland sites, J. Geophys. Res.-Atmos., 108, https://doi.org/10.1029/2002JD003319, 2003.

Gow, A. J.: Deep core studies of the accumulation and densification of snow at Byrd station and Little America V, Antarctica, CRREL Research Report 197, 1968.

Grachev, A. M. and Severinghaus, J. P.: Determining the thermal diffusion factor for Ar-40/Ar-36 in air to aid paleoreconstruction of abrupt climate change, J. Phys. Chem., 107, 4636-4642, 2003.

Guillevic, M., Bazin, L., Landais, A., Kindler, P., Orsi, A., MassonDelmotte, V., Blunier, T., Buchardt, S. L., Capron, E., Leuenberger, M., Martinerie, P., Prié, F., and Vinther, B. M.: Spatial gradients of temperature, accumulation and $\delta^{18} \mathrm{O}$-ice in Greenland over a series of Dansgaard-Oeschger events, Clim. Past, 9, 1029-1051, https://doi.org/10.5194/cp-9-1029-2013, 2013.

Hagenmuller, P., Chambon, G., and Naaim, M.: Microstructurebased modeling of snow mechanics: a discrete element approach, The Cryosphere, 9, 1969-1982, https://doi.org/10.5194/tc-91969-2015, 2015.

Helsen, M. M., van den Broeke, M. R., van de Wal, R. S. W., van de Berg, W. J., van Meijgaard, E., Davis, C. H., Li, Y., and Goodwin, I.: Elevation Changes in Antarctica Mainly Determined by Accumulation Variability, Science, 320, 1626-1629, https://doi.org/10.1126/science.1153894, 2008.

Herron, M. M. and Langway, C. C.: Firn densification: an empirical model, J. Glaciol., 25, 373-385, 1980.

Hörhold, M. W., Laepple, T., Freitag, J., Bigler, M., Fischer, H., and Kipfstuhl, S.: On the impact of impurities on the densification of polar firn, Earth Planet. Sc. Lett., 325, 93-99, 2012.

Jacka, T. H. and Li, J.: The steady-state crystal size of deforming ice, Ann. Glaciol., 20, 13-18, 1994.

Jouzel, J.: Magnitude of isotope/temperature scaling for interpretation of central Antarctic ice cores, J. Geophys. Res., 108, 4361, https://doi.org/10.1029/2002JD002677, 2003.

Jouzel, J., Masson-Delmotte, V., Cattani, O., Dreyfus, G., Falourd, S., Hoffmann, G., Minster, B., Nouet, J., Barnola, J. M., Chappellaz, J., Fischer, H., Gallet, J. C., Johnsen, S., Leuenberger, M., Loulergue, L., Luethi, D., Oerter, H., Parrenin, F., Raisbeck, G., Raynaud, D., Schilt, A., Schwander, J., Selmo, E., Souchez, R., Spahni, R., Stauffer, B., Steffensen, J. P., Stenni, B., Stocker, T. F., Tison, J. L., Werner, M., and Wolff, E. W.: Orbital and Millennial Antarctic Climate Variability over the Past 800,000 Years, Science, 317, 793-796, https://doi.org/10.1126/science.1141038, 2007.

Jung, K.-H., Park, S.-C., Kim, J.-H., and Kang, H.: Vertical diffusion of water molecules near the surface of ice, J. Chem. Phys., 121, https://doi.org/10.1063/1.1770518, 2004.

Kapsner, W. R., Alley, R. B., Shuman, C. A., Anandakrishnan, S., and Grootes, P. M.: Dominant influence of atmospheric circulation on snow accumulation in Greenland over the past 18,000 years, Nature, 373, 52-54, 1995.

Kawamura, K., Severinghaus, J. P., Ishidoya, S., Sugawara, S., Hashida, G., Motoyama, H., Fujii, Y., Aoki, S., and Nakazawa, 
T.: Convective mixing of air in firn at four polar sites, Earth Planet. Sc. Lett., 244, 672-682, 2006.

Kindler, P., Guillevic, M., Baumgartner, M., Schwander, J., Landais, A., and Leuenberger, M.: Temperature reconstruction from 10 to 120 kyr b2k from the NGRIP ice core, Clim. Past, 10, 887-902, https://doi.org/10.5194/cp-10-887-2014, 2014.

Köhler, P., Knorr, G., Buiron, D., Lourantou, A., and Chappellaz, J.: Abrupt rise in atmospheric $\mathrm{CO}_{2}$ at the onset of the Bølling/Allerød: in-situ ice core data versus true atmospheric signals, Clim. Past, 7, 473-486, https://doi.org/10.5194/cp-7-4732011, 2011.

Kojima, K.: Densification of seasonal snow cover, Phys. Snow Ice Proc. HUSCAP, 1, 929-952, 1967.

Landais, A., Barnola, J. M., Kawamura, K., Caillon, N., Delmotte, M., Van Ommen, T., Dreyfus, G., Jouzel, J., Masson-Delmotte, V., Minster, B., Freitag, J., Leuenberger, M., Schwander, J., Huber, C., Etheridge, D., and Morgan, V.: Firn-air $\delta^{15} \mathrm{~N}$ in modern polar sites and glacial-interglacial ice: a model-data mismatch during glacial periods in Antarctica?, Quaternary Sci. Rev., 25, 49-62, https://doi.org/10.1016/j.quascirev.2005.06.007, 2006.

Landais, A., Dreyfus, G., Capron, E., Jouzel, J., Masson-Delmotte, V., Roche, D. M., Prié, F., Caillon, N., Chappellaz, J., Leuenberger, M., Lourantou, A., Parrenin, F., Raynaud, D., and Teste, G.: Two-phase change in $\mathrm{CO}_{2}$, Antarctic temperature and global climate during Termination II, Nat. Geosci., 6, 1062-1065, https://doi.org/10.1038/ngeo1985, 2013.

Li, J. and Zwally, H. J.: Modeling the density variation in the shallow firn layer, Ann. Glaciol., 38, 309-313, 2004.

Ligtenberg, S. R. M., Medley, B., Van Den Broeke, M. R., and Munneke, P. K.: Antarctic firn compaction rates from repeat-track airborne radar data: II. Firn model evaluation, Ann. Glaciol., 56, 167-174, https://doi.org/10.3189/2015AoG70A204, 2015.

Lipenkov, V. Y., Barkov, N. I., Duval, P., and Pimienta, P.: Crystalline texture of the $2083 \mathrm{~m}$ ice core at Vostok Station, Antarctica, J. Glaciol., 35, 392-398, 1989.

Loulergue, L., Parrenin, F., Blunier, T., Barnola, J.-M., Spahni, R., Schilt, A., Raisbeck, G., and Chappellaz, J.: New constraints on the gas age-ice age difference along the EPICA ice cores, 050 kyr, Clim. Past, 3, 527-540, https://doi.org/10.5194/cp-3-5272007, 2007.

Loulergue, L., Schilt, A., Spahni, R., Masson-Delmotte, V., Blunier, T., Lemieux, B., Barnola, J.-M., Raynaud, D., Stocker, T. F., and Chappellaz, J.: Orbital and millennial-scale features of atmospheric $\mathrm{CH}_{4}$ over the past 800,000 years, Nature, 453, 383386, https://doi.org/10.1038/nature06950, 2008.

Lundin, J., Stevens, C., Arthern, R., Buizert, C., Orsi, A., Ligtenberg, S., and Waddington, E.: Firn Model Intercomparison Experiment (FirnMICE), J. Glaciol., 63, 401-422, https://doi.org/10.1017/jog.2016.114, 2017.

Lüthi, D., Le Floch, M., Bereiter, B., Blunier, T., Barnola, J.-M., Siegenthaler, U., Raynaud, D., Jouzel, J., Fischer, H., Kawamura, K., and Stocker, T. F.: High-resolution carbon dioxide concentration record 650,000-800,000 years before present, Nature, 453, 379-382, https://doi.org/10.1038/nature06949, 2008.

Maeno, N. and Ebinuma, T.: Pressure sintering of ice and its implication to the densification of snow at polar glaciers and ice sheets, J. Phys. Chem., 87, 4103-4110, 1983.
Marcott, S. A., Bauska, T. K., Buizert, C., Steig, E. J., Rosen, J. L., Cuffey, K. M., Fudge, T. J., Severinghaus, J. P., Ahn, J., Kalk, M. L., McConnell, J. R., Sowers, T., Taylor, K. C., White, J. W. C., and Brook, E. J.: Centennial-scale changes in the global carbon cycle during the last deglaciation, Nature, 514, 616-619, https://doi.org/10.1038/nature13799, 2014.

Martinerie, P., Raynaud, D., Etheridge, D. M., Barnola, J.-M., and Mazaudier, D.: Physical and climatic parameters which influence the air content in polar ice, Earth Planet. Sc. Lett., 112, 1-13, 1992.

Martinerie, P., Lipenkov, V. Y., Raynaud, D., Chappellaz, J., Barkov, N. I., and Lorius, C.: Air content paleo record in the Vostok ice core (Antarctica): A mixed record of climatic and glaciological parameters, J. Geophys. Res.-Atmos., 99, 10565-10576, 1994.

Mellor, M.: Properties of snow, CRREL Monograph, Section IIIA1, 1964.

Miller, D. A., Adams, E. E., and Brown, R. L.: A microstructural approach to predict dry snow metamorphism in generalized thermal conditions, Cold Reg. Sci. Technol., 37, 213-226, https://doi.org/10.1016/j.coldregions.2003.07.001, 2003.

Morgan, V. I.: High-temperature ice creep tests, Cold Reg. Sci. Technol., 19, 295-300, 1991.

Nie, S., Bartelt, N. C., and Thürmer, K.: Observation of Surface Self-Diffusion on Ice, Phys. Rev. Lett., 102, 136101, https://doi.org/10.1103/PhysRevLett.102.136101, 2009.

Orsi, A. J., Cornuelle, B. D., and Severinghaus, J. P.: Magnitude and temporal evolution of Dansgaard-Oeschger event 8 abrupt temperature change inferred from nitrogen and argon isotopes in GISP2 ice using a new least-squares inversion, Earth Planet. Sc. Lett., 395, 81-90, 2014.

Overly, T. B., Hawley, R. L., Helm, V., Morris, E. M., and Chaudhary, R. N.: Greenland annual accumulation along the EGIG line, 1959-2004, from ASIRAS airborne radar and neutronprobe density measurements, The Cryosphere, 10, 1679-1694, https://doi.org/10.5194/tc-10-1679-2016, 2016.

Parrenin, F., Dreyfus, G., Durand, G., Fujita, S., Gagliardini, O., Gillet, F., Jouzel, J., Kawamura, K., Lhomme, N., MassonDelmotte, V., Ritz, C., Schwander, J., Shoji, H., Uemura, R., Watanabe, O., and Yoshida, N.: 1-D-ice flow modelling at EPICA Dome C and Dome Fuji, East Antarctica, Clim. Past, 3, 243-259, https://doi.org/10.5194/cp-3-243-2007, 2007.

Parrenin, F., Petit, J.-R., Masson-Delmotte, V., Wolff, E., BasileDoelsch, I., Jouzel, J., Lipenkov, V., Rasmussen, S. O., Schwander, J., Severi, M., Udisti, R., Veres, D., and Vinther, B. M.: Volcanic synchronisation between the EPICA Dome $\mathrm{C}$ and Vostok ice cores (Antarctica) 0-145 kyr BP, Clim. Past, 8, 1031-1045, https://doi.org/10.5194/cp-8-1031-2012, 2012.

Pimienta, P.: Etude du comportement mécanique des glaces polycristallines aux faibles contraintes: applications aux glaces des calottes polaires, $\mathrm{PhD}$ Thesis, Université Scientifique Technologique et Médicale de Grenoble, 166 pp., 1987.

Pimienta, P. and Duval, P.: Rate controlling processes in the creep of the polar glacier ice, J. Phys. Colloq., 48, C1-243-C1-248, https://doi.org/10.1051/jphyscol:1987134, 1987.

Proksch, M., Rutter, N., Fierz, C., and Schneebeli, M.: Intercomparison of snow density measurements: bias, precision, and vertical resolution, The Cryosphere, 10, 371-384, https://doi.org/10.5194/tc-10-371-2016, 2016. 
Ramseier, R. O.: Self-diffusion in ice monocrystals, CRREL Research Report no 232, 1967.

Rasmussen, S. O., Andersen, K. K., Svensson, A. M., Steffensen, J. P., Vinther, B. M., Clausen, H. B., Siggaard-Andersen, M.L., Johnsen, S. J., Larsen, L. B., Dahl-Jensen, D., Bigler, M., Röthlisberger, R., Fischer, H., Goto-Azuma, K., Hansson, M. E., and Ruth, U.: A new Greenland ice core chronology for the last glacial termination, J. Geophys. Res., 111, D06102, https://doi.org/10.1029/2005JD006079, 2006.

Rhodes, R. H., Brook, E. J., Chiang, J. C., Blunier, T., Maselli, O. J., McConnell, J. R., Romanini, D., and Severinghaus, J. P.: Enhanced tropical methane production in response to iceberg discharge in the North Atlantic, Science, 348, 1016-1019, 2015.

Salamatin, A. N., Lipenkov, V. Y., Barnola, J. M., Hori, A., Duval, P., and Hondoh, T.: Snow/firn densification in polar ice sheets, Phys. Ice Core Rec. - II, 68, 195-222, 2009.

Schwander, J.: The transformation of snow to ice and the occlusion of gases, Environ. Rec. Glaciers Ice Sheets, 8, 53-67, 1989.

Schwander, J., Barnola, J. M., Andrié, C., Leuenberger, M., Ludin, A., Raynaud, D., and Stauffer, B.: The age of the air in the firn and the ice at Summit, Greenland, J. Geophys. Res.-Atmos., 98, 2831-2838, 1993.

Schwander, J., Sowers, T., Barnola, J.-M., Blunier, T., Fuchs, A., and Malaizé, B.: Age scale of the air in the summit ice: Implication for glacial-interglacial temperature change, J. Geophys. Res.-Atmos., 102, 19483-19493, 1997.

Severinghaus J. P. and Battle M. O.: Fractionation of gases in polar ice during bubble close-off: New constraints from firn air $\mathrm{Ne}$, $\mathrm{Kr}$ and Xe observations, Earth Planet. Sci. Lett., 244, 474-500, 2006.

Severinghaus, J. P., Sowers, T., Brook, E. J., Alley, R. B., and Bender, M. L.: Timing of abrupt climate change at the end of the Younger Dryas interval from thermally fractionated gases in polar ice, Nature, 391, 141-146, 1998.

Sime, L. C., Wolff, E. W., Oliver, K. I. C., and Tindall, J. C.: Evidence for warmer interglacials in East Antarctic ice cores, Nature, 462, 342-346, 2009.
Sowers, T., Bender, M., and Raynaud, D.: Elemental and isotopic composition of occluded $\mathrm{O}_{2}$ and $\mathrm{N}_{2}$ in polar ice, J. Geophys. Res.-Atmos., 94, 5137-5150, 1989.

Sowers, T., Bender, M., and Korotkevich, Y.: $\delta^{15} \mathrm{~N}$ of $\mathrm{N}_{2}$ in Air Trapped in Polar ice, J. Geophys. Res., 97, 615-683, 1992.

Veres, D., Bazin, L., Landais, A., Toyé Mahamadou Kele, H., Lemieux-Dudon, B., Parrenin, F., Martinerie, P., Blayo, E., Blunier, T., Capron, E., Chappellaz, J., Rasmussen, S. O., Severi, M., Svensson, A., Vinther, B., and Wolff, E. W.: The Antarctic ice core chronology (AICC2012): an optimized multi-parameter and multi-site dating approach for the last 120 thousand years, Clim. Past, 9, 1733-1748, https://doi.org/10.5194/cp-9-17332013, 2013.

WAIS Divide Project Members: Onset of deglacial warming in West Antarctica driven by local orbital forcing, Nature, 500, 440-444, https://doi.org/10.1038/nature12376, 2013.

WAIS Divide Project Members: Precise interpolar phasing of abrupt climate change during the last ice age, Nature, 520, 661-665, 2015.

Wilkinson, D. S. and Ashby, M. F.: Pressure sintering by power law creep, Acta Metall., 23, 1277-1285, 1975.

Witrant, E., Martinerie, P., Hogan, C., Laube, J. C., Kawamura, K., Capron, E., Montzka, S. A., Dlugokencky, E. J., Etheridge, D., Blunier, T., and Sturges, W. T.: A new multi-gas constrained model of trace gas non-homogeneous transport in firn: evaluation and behaviour at eleven polar sites, Atmos. Chem. Phys., 12, 11465-11483, https://doi.org/10.5194/acp-12-114652012, 2012. 